\title{
Poblamiento rural en el territorium de Tarraco durante la antigüedad tardía *
}

\author{
Alexandra Chavarría Arnau ***
}

\begin{abstract}
RESUMEN
Análisis de las características, evolución y transformaciones de las uillae situadas en el territorium de Tarraco durante la antigüedad tardía.
\end{abstract}

PALABRAS CLAVE: Uillae. Transformaciones. Tarraco. Antigüedad tardía.

Los cambios que tuvieron lugar en las ciudades de Hispania durante la antigüedad tardía empiezan a ser bien conocidos y han sido objeto de un gran número de publicaciones en los últimos años !. Del mismo modo, en el campo se documentan a partir del siglo $\vee$ cambios importantes que provocaron la transformación, cambio de función y posterior desaparición de muchas de las estructuras

\begin{abstract}
Analysis of the characteristics, evolution and transformations of the Roman uillae situated on the territory of Tarraco during Late Antiquity.
\end{abstract}

KEY WORDS: Uillae. Transformations. Tarraco. Late Antiquity.

arquitectónicas que habían caracterizado el paisaje rural romano. Sin embargo este proceso ha sido poco estudiado y las transformaciones que experimentaron estos edificios raramente han sido objeto de análisis y mucho menos interpretados en modo distinto a las tradicionales explicaciones vinculadas a los conceptos de crisis y decadencia del Imperio que, como están demostrando las líneas de investigación

\footnotetext{
* El presente estudio es fruto de dos trabajos presentados al Primer y Segundo Seminario: Transformación y problemas del territorio en época tardorromana en Hispania, celebrados en 1997 y 1998 en la Universidad Rovira i Virgili de Tarragona. Agradezco a Javier Arce el haberme invitado a participar en dichas reuniones y a Gisela Ripoll por las sugerencias hechas a este texto.

*** IEMAN (Universität Paderborn).

I La bibliografía es muy amplia, como más significativos cfr. los volúmenes de J. Rich (ed.), The City in Late Antiquity, Londres, 1992; G. P. Brogiolo (ed.), Early Medieval Towns in the Western Mediterranean (Ravello, 1994), Mantova, 1996; N. Christie y S. T. Loseby (eds.), Towns in Transition, Urban Evolution in Late Antiquity and the Early Middle Ages, Aldershot, 1996; Cl. Lepelley (ed.). La fin de la Cité Antique et le début de la cité médiévale, Bari, 1996; G. Ripoll y J. M. Gurt (eds.). Sedes Regiae (ann. 400-800). Barcelona, 2000. Todos ellos recogen análisis sobre problemáticas específicas o ejemplos concretos de ciudades durante la antigüedad tardía. Para Hispania cabe destacar los trabajos de J. Arce, "La ciudad en la España tardorromana: icontinuidad o discontinuidad?", en Ciudad y comunidad cívica en Hispania (s. II y III d.C.). Casa de Velázquez, CSIC, Madrid, 1993, pp. 177- |88; I. Mª Gurt, G. Ripoll y C. Godoy, "Topografía de la antigüedad tardía hispánica. Reflexiones para una propuesta de trabajo", AntiquitéTardive, 2, 1994, pp. I6I - I80 y S. Gutiérrez, "Le città della Spagna tra romanità e islamismo", en G. P. Brogiolo (ed.), 1996, cit., pp. 55-66, así como algunos de los trabajos que componen el volumen de G. Ripoll y J. M. Gurt (eds.), 2000, cit.
} 
actuales, merecen ser objeto de una profunda revisión ${ }^{2}$. Por lo general gran parte de los fenómenos que se producen en las uillae son explicados en relación a la evolución de los núcleos urbanos: el embellecimiento de las instalaciones residenciales se asocia al abandono de las ciudades por parte de las élites urbanas; el aumento de las instalaciones productivas se entiende como sinónimo de autosuficiencia y desvinculación entre campo y ciudad, etc. sin que, en la mayor parte de casos, se posea un conocimiento preciso de lo que está sucediendo en un determinado núcleo urbano cuando se estudian los establecimientos rurales de su territorio.

El objetivo de este trabajo es analizar las características y evolución de las uillae ubicadas en el territorio de Tarraco durante la antigüedad tardía prestando especial atención a las transformaciones arquitectónicas y funcionales que en ellas se documentan y poniendo en relación estos cambios con la información existente respecto al comportamiento evolutivo de la ciudad.

\section{EL TERRITORIUM DE TARRACO}

Es posible determinar con relativa precisión cuál era el territorium de la ciudad de Tarraco en época romana. Teniendo en cuenta los núcleos urbanos más próximos, las características orográficas y algunos elementos de carácter histórico, arqueológico y epigráfico, se sitúa el límite norte del ager tarraconensis en las proximidades de la ciudad de Barcino y concreta- mente en la actual población de Martorell, identificada como la mansio ad fines citada en los itinerarios de los vasos de Vicarello ${ }^{3}$, mientras que al sur y oeste el territorio estaría delimitado por la cordillera prelitoral y la del Gaiá. El ager de la ciudad de Tarraco abarcaría según esta propuesta las actuales comarcas del Tarragonés, Alt y Baix Camp, Alt y Baix Penedés y Garraf. Se trata de una zona básicamente llana surcada por los ríos Gaià, Francolí y sus correspondientes rieras (cfr. fig. I). El análisis del parcelario actual y de la cartografía histórica permite identificar (al menos en la zona denominada El Camp de Tarragona) una estructura parcelaria de época romana bastante regular en las zonas llanas mientras que en el resto se percibe la influencia de los cursos de agua y el relieve ${ }^{4}$.

Como correspondía a su condición de capital provincial Tarraco estaba bien comunicada con el resto de ciudades de Hispania gracias a la Vía Augusta y a la calzada que desde Tarraco conducía a llerda y Caesaraugusta.

\section{CARACTERÍSTICAS DE LOS ESTABLECIMIENTOS RURALES DEL TERRITORIO DE TARRACO}

Tanto la documentación textual como la arqueológica ofrecen datos parciales para el análisis del mundo rural. Las fuentes textuales referentes al ager tarraconensis son escasas y los vestigios arqueológicos suelen pertenecer a grandes estructuras (almacenes, edificios dedicados a actividades productivas y estructuras de carácter residencial) mientras

\footnotetext{
2 Excepciones notables son los trabajos de G. Webster, "The Future of Villa Studies", en A. L. F. Rivet (ed.), The Roman Villa in Britain, Londres, 1969, pp. 217-249; T. Lewit, Agricultural Production in the Roman Economy A.D. 200-400, BAR, IS, 568, Oxford, 1991; P. Van Ossel, Etablissements ruraux de l'Antiquité tardive dans le nord de la Gaule, París, 1992; K. Branigan, The Roman Villa in South West England, Bradford-on-Avon, 1976, especialmente pp. 93- 108; G. P. Brogiolo (ed.), La fine delle ville romane: transformazioni nelle campagne tra tarda antichità e alto medioevo, $1^{\circ}$ Convegno Archeologico del Garda, Documenti di Archeologia, II, Mantova, 1996. Para una revisión de los principales problemas en la pars occidentis cfr. el artículo de G. Ripoll y J. Arce en este mismo volumen.

3 Para estas cuestiones ver X. Dupré i Raventós, L'Arc romà de Berà, IEC-CSIC, Barcelona, 1994, pp. 247-253. Otros investigadores prefieren situar el límite norte del territorium de Tarraco a la altura de la vía Augusta donde se erigió el arco de Berà (S. J. Keay, "The Ager Tarraconensis in the Late Empire: a model for the economic relationship of town and country in eastern Spain", en G. Baker y J. Lloyd (eds.), Roman Landscapes: archeological Survey in the Mediterranean Region, Archaeological Monographs of the British School at Rome, 2, 1991, pp. 79-87).

4 E. Ariño, J. M. Gurt, M. A. Martín Bueno, "Les cadastres romains d'Hispanie. Etat actuel de la recherche", en P. N. Doukellis y L. G. Mendoni (ed.), Structures rurales et sociétés antiques, Actes du colloque de Corfu (1992), Centre de Recherches d'Histoire Ancienne, 126, Annales Littéraires de I'Université de Besançon, 508, París, 1994, pp. 321-322.
} 
que la mayoría de elementos que seguramente conformaban el paisaje (pequeñas granjas y aldeas) han desaparecido dada la caducidad de los materiales con que se habían construido y que las hacen poco evidentes al registro arqueológico.

Los establecimientos rurales analizados se sitúan prevalentemente junto a las vías de comunicación terrestres y fluviales, es decir, junto a la costa y a lo largo de los principales ríos que surcan el territorio analizado.

La mayor parte de establecimientos corresponde a edificios de medianas dimensiones, dotados de un sector de hábitat y estructuras de función rústica situadas a poca distancia o en el mismo edificio que la zona de hábitat. Las uillae del Castell de Cubelles (Garraf) ${ }^{5}$, La Solana (Cubelles, Garraf), La Rectoría (Pacs del Penedés) ${ }^{6}$, El Moro (Torredembarra) ${ }^{7}$, Els Hospitals (El Morell) ${ }^{8}$ y La Llosa (Cambrils) ${ }^{9}$ son los ejemplos mejor conocidos (cf. Fig. I).

Además de estos establecimientos de carácter más bien modesto y con una función bási- camente productiva, se encuentran grandes estructuras en las que destaca la existencia de un importante sector residencial articulado con frecuencia a partir de un peristilo o jardín y dotado de grandes habitaciones, conjuntos termales y un aparato decorativo del que conocemos los pavimentos musivos, pinturas murales y conjuntos escultóricos. Darró (Vilanova i la Geltrú) ${ }^{10}$, Els Munts (Altafulla) ${ }^{\prime \prime}$, Centcelles (Constantí) ${ }^{12}$, Paretdelgada (La Selva del Camp) ${ }^{13}$ y Cal-lípolis (Vila-Seca) ${ }^{14}$ son las principales uillae documentadas en este territorio. Destaca el hecho que, a excepción de Darró, el resto de uillae se sitúa en el territorio inmediato de la ciudad de Tarraco. Estos edificios eran los centros de medianas o grandes explotaciones y constituían lugares de residencia más o menos temporales donde el propietario disfrutaba de sus momentos de ocio ${ }^{15}$.

En relación a estos edificios residenciales aparecen a veces estructuras dedicadas a funciones productivas (almacenes, talleres, establos, etc.) y, en algunas ocasiones, edificios de hábitat que podrían identificados con las casas de los responsables o encargados de la explota-

5 A. López, X. Fierro y A. Caixal, “Un nou jaciment a l'ager de Tarraco: la vil·la romana del Castell de Cubelles", Hispania i Roma. D'August a Carlemany. Congrés d'homenatge al Dr. Pere de Palol, Girona 23, 24 i 25 de novembre de 1995, Annals de l'Institut d'Estudis Gironins, vol. XXXVII, Girona, 1997, pp. 853-873.

6 J. G. Gorges, Les villas hispano-romaines. Inventaire et problématique archéologiques, París, 1979, p. 49 y pp. 21 I-212 y A. Balil, “La villa romana de Pacs (Penedès, Barcelona)", Boletín del Seminario de Estudios de Arte y Arqueología, Valladolid, 1987, pp. I8I-189.

7 Anuari d'intervencions arqueològiques a Catalunya. Època romana-Antiguitat tardana. Campanyes 1982-1989, Generalitat de Catalunya, Barcelona, 1993, p. 266.

8 J. M. Macias, et alii, "Nous contextos ceràmics del segle IV i inicis del V en la provincia de Tarragona", Contextos ceràmics d'època romana tardana i de l'alta edat mitjana (segles IV-X). Actes de la Taula Rodona organitzada a Barcelona els dies 6, 7 i 8 de novembre de 1996, ArqueoMediterrània, 2, Barcelona, 1997, pp. 153- 177.

9 J. Massó y E. Ramón, “La vil·la romana de 'la Llosa”, Revista Cambrils, I50, 1993, pp. 357-373.

10 A. López y J. Fierro, “La época romana en Darró (Vilanova i la Geltrú, Barcelona)”, ETF, s. I, t. 3, Madrid, 199I, pp. $203-254$.

II M. Berges, "Informe sobre Els Munts", Boletín Arqueológico, IV, 4, 1969-70, pp. I40-I 50; M. Berges, "Nuevo informe sobre Els Munts", Estudis Altafullencs, I, 1977, pp. 27-47; J. López, "Les termes inferiors de la vil·la romana dels Munts", Utilització de l'aigua a les ciutats romanes, Documents d'Arqueologia Clàssica, 0, Tarragona, 1993, pp. 56-79; F. Tarrats, E. Ramón, y J. M. Macias, “Noves intervencions a la vil·la romana dels Munts (Altafulla), Tarragonés", Tribuna d'Arqueologia 1996-97, Barcelona, I997, pp. 35-56 y F. Tarrats, et alii, 1998: "Excavacions a l'àrea residencial de la vil·la romana dels Munts (Altafulla, Tarragonès), Empúries, 51, pp. $197-225$.

12 Como obras de carácter general sobre este yacimiento ver $\mathrm{H}$. Schlunk, Die Mosaikkupel von Centcelles, 2 vols., Maguncia, 1988 y T. Hauschild y A. Arbeiter, La vil·la romana de Centcelles, Barcelona, 1993, ambos con bibliografía anterior.

13 J. Guitert, "Descubriments romans a Pared Delgada", Boletín Arqueológico, III, 5, 1936, pp. I37-I4I.

14 J. M. Macias y F. Tuset, "Excavacions arqueològiques a la vil·la romana de Cal·lípolis (Vila-Seca, Tarragona)", Tribuna d'Arqueologia 1994-1995, Barcelona, 1996, pp. II3-121.

15 Véase con carácter general J. Arce, "Otium et negotium: the great estates. 4th-7th century", en L. Webster y M. Brown (eds.), The Transformation of the Roman World, AD 400-900, TRW, 1995, pp. 19-32, donde se estudian las características de las uillae tardoantiguas, su decoración, actividades e ideología de los propietarios así como otras problématicas analizadas por las líneas de investigación actuales. En relación a las características arquitectónicas de las uillae en general cfr. A. Carandini, "La villa romana e la piantagione schiavistica", Storia di Roma. Caratteri e Morfologie, 4, Turín, 1989, pp. 101-200. 
ción. Es posible, por ejemplo, que la uilla de Centcelles - de la que conocemos un conjunto termal y varias estancias de recepción- se trate sólo de una parte de un conjunto residencial más amplio que constituiría el centro administrativo de un amplio fundus dotado de distintas estructuras y edificios anexos como parecen mostrar los hallazgos de numerosos yacimientos en el término de Constantí como Mas Serapi, Mas dels Frares, Les Tries o Sant Llorenç con características y funciones distintas que se prodrían identificar como granjas y estructuras relacionadas con la uilla de Centcelles (Lámina I).

\section{EVOLUCIÓN DE LOS ESTABLECIMIENTOS RURALES EN EL TERRITORIO DE TARRACO}

\section{Orígenes}

La primera implantación de establecimientos rurales romanos en el suburbium y el territorio de Tarraco se sitúa en época republicana o, más frecuentemente, en época de Augusto coincidiendo con la primera monumentalización de la ciudad. En la zona situada entre el río Francolí y el sector occidental de la ciudad se construyen varias uillae suburbanas y estructuras dedicadas a la producción y el almacenaje ${ }^{16}$. En el territorio los vestigios de estos primeros establecimientos (depósitos, cisternas, hornos, canalizaciones, dolia, etc.) indican que se trata de pequeñas granjas dedicadas a actividades agrícolas combinada frecuentemente con la producción cerámica y anfórica (Mas Pórpores, Els Antigons, Darró) 17.
Durante los siglos II y III estas estructuras se consolidan, amplían y se distingue un sector residencial más destacado, dotado de termas y programas decorativos de los que se conservan vestigios de la decoración musiva, pictórica y de los programas escultóricos o del mobiliario metálico. La fase de mayor desarrollo de la uilla de Els Munts se fecha, según las últimas intervenciones, en los siglos II y primera mitad del siglo III, cronología que se da a las pinturas, mosaicos y esculturas que decoraban las habitaciones del sector residencial ${ }^{18}$. Una cronología similar se da a la fase de mayor esplendor (al menos en cuanto a residencia) de La Llosa, cuando sus habitaciones estaban decoradas con pinturas murales, placas de mármol y mobiliario metálico ${ }^{19}$. También en Cal'lípolis la instalación de un gran mosaico con representación de peces datado en el segundo cuarto del s. II 20 muestra como este momento representa una fase de embellecimiento de las estructuras residenciales de esta uilla.

\section{Las transformaciones del siglo III}

Se tiene poca información arqueológica sobre el desarrollo de Tarraco a partir del siglo III. Un fenómeno importante es la ocupación de la parte occidental del suburbium de la ciudad por zonas funerarias que, en algunos casos, se instalan sobre uillae suburbanas o establecimientos dedicados a producción preexistentes que habían sido abandonados. La uilla de la calle Robert Aguiló 21, la del Parc de la Ciutat ${ }^{22}$, las estructuras de la calle Pere Martell ${ }^{23}$, el edificio de la calle Fernández Sanahuja ${ }^{24}$ y la uilla

\footnotetext{
16 M. Terré, “Una aproximació a l'ocupació suburbana del sector oest de Tarraco”, Acta Arqueológica de Tarragona II (I989-1990), Tarragona, 1990, pp. 47-55.

17 Sobre esta primera fase ver las aportaciones de O. Olesti Vila, "El origen de las uillae romanas en Cataluña", Archivo Español de Arqueología, 70, 1997, pp. 71-90.

I8 Lo más reciente sobre esta fase en F. Tarrats Et alii, "Nuevas actuaciones en el área residencial de la uilla romana de Els Munís (Altagulla, Ager Tarraconensis)", Madrider Mitteilungen, 4I, 2000, pp. 358-379 y E.M. Koppel, "Informe preliminar sobre la decoración escultórica de la villa romana de Els Munís (Altagulla, Tarragona)", Madrider Mitteilungen, 4I, 2000, pp. 380-394.

19 Massó y Ramón, 1993, cit.

20 M. Bobadilla, "El mosaico de peces de la Pineda (Tarragona)", Pyrenae, 5, 1969, pp. |4|-I53.

21 Anuari d'intervencions arqueològiques a Catalunya, 1993, cit., p. 254.

22 TED'A, Els enterraments del Parc de la Ciutat i la problemàtica funerària de Tarraco, Memòries d'Excavació, I, Tarragona, 1987.

23 Anuari d'intervencions arqueològiques a Catalunya, 1993, cit., pp. 255-259.

24 Anuari d'intervencions arqueològiques a Catalunya, 1993, cit., p. 262.
} 
de la calle Ramón y Cajal 24-26 25 son algunos ejemplos por ahora conocidos.

En el territorio se constata el abandono de algunos establecimientos (El Moro en Torredembarra por ejemplo) así como algunos incendios en sectores de edificios durante la segunda mitad del siglo III después de los cuales las uillae experimentan mutaciones importantes que afectan a su estructura y función primitiva como sucede en Els Munts. En otros yacimientos (como Cal-lípolis) se detecta una cierta reducción de las instalaciones dedicadas a producción que, en ocasiones, quedan parcial o totalmente abandonadas.

Estos cambios que experimentan las uillae desde la segunda mitad del siglo III (abandonos, incendios, reconstrucciones, nuevos programas decorativos) se interpretaban tradicionalmente como consecuencia del devastante paso de las tribus francas por el territorio de Tarraco que, según las fuentes literarias, tuvo lugar hacia el año 260-26I 26. Actualmente, la hipótesis de la destrucción de establecimientos puede ser matizada y se ha demostrado que en muchos edificios los elementos que se consideraban como pruebas de aquellas destrucciones (estratos de cenizas, tesorillos y transformaciones arquitectónicas) son cronológicamente posteriores y no pueden relacionarse con el fenómeno histórico de las inva- siones. Quizás una excepción sea la uilla de Els Munts donde las últimas excavaciones han documentado la destrucción de parte del sector residencial por un incendio cuya cronología se ha podido situar, gracias a material cerámico y numismático, en los años 260-270 27, coincidiendo con las noticias dadas por los historiadores sobre el paso de las tribus francas por el ager tarraconensis. Aun así, no existe ningún elemento -aparte de la coincidencia cronológica- que vincule a la destrucción con los bárbaros.

Otra línea de investigación más reciente asume que el embellecimiento de las uillae está en relación directa con la crisis del siglo III y el supuesto abandono de las ciudades por parte de las élites urbanas. Según esta interpretación la destrucción de las ciudades, la inseguridad y la crisis económica, habrían dado lugar a un debilitamiento de la vida urbana y el traslado de la población al campo donde se desarrollaría una economía de autoabastecimiento y autarquía mientras que las ciudades pasarín a depender casi de modo exclusivo de las importaciones 28. El análisis comparado de los materiales cerámicos de la ciudad y del territorio demostraría, según S. Keay, que tras la crisis del siglo III y durante la antigüedad tardía se produce una ruptura en las relaciones entre la ciudad y su territorium que siguen circuitos económicos y comerciales distintos ${ }^{29}$.

25 Anuari d'intervencions arqueològiques a Catalunya, 1993, cit., p. 260.

26 Un análisis crítico de estas fuentes y la interpretación de los materiales arqueológicos a partir de estos textos en J. Arce, "La crisis del siglo III d.C. en Hispania y las invasiones bárbaras", Hispania Antiqua, 8, 1978, pp. 257-269. Más reciente A. Cepas, Crisis y continuidad en la Hispania del siglo III, Anejos de AEspA, XVII, CSIC, Madrid, 1997.

27 El conjunto de monedas se analiza en T. Marot, "El conjunt de sestercis del segle III", en F. Tarrats, et alii, cit., I998, pp. 218-220 y T. Marot y E. Riu, "Conjunt monetari de la vil·la dels Munts", Del romà al romànic. Història, Art i Cultura de la Tarraconense Mediterrània entre els segles IV i X, P. de Palol y A. Pladevall (eds.), Fundació Enciclopèdia Catalana, Barcelona, 1999, p. 34I.

28 S. Keay, "The Conventus Tarraconensis in the Third Century A. D.: Crisis or Change?", en A. King y M. Henig (eds.), The Roman West in the Third Century. Contributions from Archaeology and History, BAR, IS, 109, Oxford, 1981, p. 464.

29 A partir de las ánforas procedentes de vertederos urbanos y del material obtenido a partir de prospecciones en el territorio (Carreté, Keay y Millet, 1995, cit.). Las cerámicas documentadas en contextos urbanos (básicamente vertederos) han sido objeto de importantes estudios. Sobre las sigillatas africanas destaca la tesis de X. Aquilué, Relaciones económicas, sociales e ideológicas entre el norte de África y la Tarraconense en época romana. Las cerámicas de producción africana procedentes de la Colonia Urbs Triumphalis Tarraco, Colecció de Tesis Doctorals Microfitxades, núm. 1275, Barcelona, 1992. El análisis de los materiales anfóricos se debe fundamentalmente a S. Keay, Late Roman Amphorae in the Western Mediterranean: a typology and economic Study: the Catalan Evidence, BAR, IS, 196, Oxford, 1984 y J. A. Remolà i Vallverdú, Las ánforas tardoantiguas en Tarraco (Hispania Tarraconensis). Siglos IV-VII, Tulcis, Monografías Tarraconenses, Tarragona, 1999. El estudio de la cerámica común en J. M. Macias Solé, La ceràmica comuna tardoantiga a Tàrraco. Anàlisi tipològica i històrica (segles V-VIII), Tulcis, Monografías Tarraconenses, Tarragona, 1999. 
Ahora bien, esta interpretación no tiene en cuenta suficientemente una serie de aspectos. Desde hace ya algunos años sabemos que la llamada "crisis del siglo III" no tuvo como consecuencia un abandono generalizado de las ciudades y que muchos núcleos urbanos (entre ellos Tarraco) continuaron siendo centros de actividad política, administrativa, comercial y religiosa hecho que implica la existencia de población y de élites urbanas que ocupaban los cargos políticos, administrativos y religiosos de la ciudad ${ }^{30}$. Estas aristocracias repartían su tiempo entre ciudad y sus propiedades rurales y por tanto es difícil plantearse el hecho que las uillae dejasen de abastecer a los centros urbanos ya que ambos medios eran controlados por las mismas personas ${ }^{31}$. Por otro lado, y como se va a intentar demostrar, la documentación arqueológica procedente tanto de los yacimientos del territorio como de contextos urbanos, parece desmentir esta supuesta desvinculación.

\section{Siglos IV y V}

Se ha visto como a partir del siglo III algunas uillae romanas del ager tarraconensis son abandonadas o-como se verá más adelantesufren transformaciones que afectan a las características y función de estos edificios. No se trata sin embargo de un fenómeno generalizado. Otras uillae siguen en activo sin cambios relevantes que alteren su carácter residencial durante todo el siglo IV y hasta, como mínimo, inicios del siglo $V$ y se dotan de nuevas estructuras y ricos programas decorativos que incrementan su confort y prestigio. Ejemplos de ello son las uillae de Darró, donde se construye una habitación con cabecera poligonal y revestimientos de mármol; Paretdelgada que es decorada con varios pavimentos musivos o Centcelles, uilla en la que se instala un nuevo conjunto termal y uno de cuyos ámbitos recibe un lujoso programa decorativo que incluye mosaicos en la cúpula y pinturas murales. Esta fase se ha fechado hasta el momento a partir del análisis estilístico de los mosaicos (en Paretdelgada y Centcelles fundamentalmente) a los que se atribuye una cronología de mediados o segunda mitad de siglo IV.

Este proceso de expansión y monumentalización de los espacios residenciales de las uillae es común a un gran número de edificios en toda Hispania y es un indicio de las inversiones realizadas en las explotaciones rurales desde finales del siglo III y fundamentalmente durante todo el siglo IV gracias al período de estabilidad política y económica por el que atraviesa la Península.

En cuanto al abandono de estas uillae tradicionalmente se ha asumido que se produce, como muy tarde a inicios del siglo V. Sin embargo, excavaciones recientes, nuevos estudios sobre los materiales arqueológicos (básicamente la cerámica) y una mejor comprensión de las particularidades de la circulación monetaria de época tardía permiten determinar que, en muchos casos, las uillae continúan en funcionamiento como tales durante, al menos, la primera mitad del siglo $\mathrm{V}$.

En yacimientos como Darró o la Solana se han podido estudiar conjuntos de material cerámico (cerámica de mesa, de cocina y ánforas) de importación fechados en la primera mitad

\footnotetext{
30 Existe una amplia bibliografía reciente que trata sobre la continuidad de la vida ciudadana durante la antigüedad tardía. Los trabajos más destacados han sido ya citados en la nota I. El caso concreto de Tarraco en S. J. Keay, "New Light on Tarragona in the Late Empire", Journal of Roman Archaeology, 4, 199I, pp. 387-397; '́d., "Tarraco in late Antiquity", en N. Christie y S. Loseby (eds.), I996, cit., pp. 18-44. J. Menchón, J. M. Macias y A. Muñoz, "Aproximació al procés transformador de la ciutat de Tarraco. Del Baix Imperi a l'Edat Mitjana", Pyrenae, 25, 1994, pp. 225-243.

3 I En palabras de C. R. Whittaker: "The rural potentes were also the urban elite who supplied much of the town's conssumption needs" (C. R. Whittaker, "The consumer city revisited: the uicus and the city", Journal of Roman Archaeology, 3, 1990, p. III). También D. Vera considera (refiriéndose a las élites urbanas) que "questa stessa aristocrazia svolge un ruolo commerciale attivo, ricava dalle sua propietà ingenti quantitativi di prodotti agricoli che vende nei centri urbani, ed è quindi inevitabilmente interessata e coinvolta nei fenomeni di mercato" (D. Vera, "Strutture agrarie e strutture patrimoniali nella tarda antichità: la aristocrazia romana fra agricoltura e commercio", Opus, II, fasc. 2, 1983, p. 49I).
} 
del siglo $\vee^{32}$. En Centcelles se ha identificado cerámica de cocina africana presente en Tarraco en niveles del siglo $V^{33}$ así como sigillata africana D con similar cronología ${ }^{34}$. De gran interés son los hallazgos realizados en el yacimiento de Els Hospitals donde aparecieron dos depósitos con abundante material cerámico de origen africano (cerámica común, sigillata africana $D^{35}$, ánforas $\left.{ }^{36}\right)$, ánforas de la Baetica ${ }^{37}$ y cerámica común local ${ }^{38}$, material que alcanza cronologías de hasta el primer cuarto del siglo $\mathrm{V}$.

Algunos hallazgos urbanos como el vertedero del foro provincial de Tarraco muestra como durante el siglo $V$ se consumían animales (ovejas, cabras y cerdos) provenientes presumiblemente del territorio así como cerámica local ${ }^{39}$. Además se empiezan a identificar en la ciudad recipientes anfóricos locales de cronología tardía (siglos IV-V) que procederían de las uillae situadas en el territorio y que habrían servido posiblemente para el transporte de vino aunque todavía no se han realizado análisis que permitan confirmar el contenido ${ }^{40}$.

Tanto los hallazgos de importación hallados en los yacimientos rurales como los materiales procedentes del territorio descubiertos en contextos urbanos son un reflejo de la conti- nuidad de los vínculos entre núcleo urbano y establecimientos rurales, al menos, hasta mediados del siglo $V$ dado que estos productos llegan y son redistribuidos desde la ciudad, que sigue siendo un centro urbano activo como demuestran tanto los hallazgos arqueológicos como las referencias en las fuentes textuales.

Uno de los hallazgos más interesantes realizados recientemente en Tarragona y que aboga por la vitalidad de la ciudad (o al menos de su suburbio inmediato) durante la antigüedad tardía, es el de la residencia suburbana situada junto a la necrópolis del Francolí y al conjunto cristiano del Parc Central (Lámina 3). Se trata de una típica estructura de peristilo al que se abren distintas habitaciones entre las que destaca un pequeño conjunto termal y una estancia dotada de cabecera semicircular. $\mathrm{Ni}$ las dimensiones ni la riqueza del edificio apoyan la denominación "villa-palacio" establecida por sus investigadores ${ }^{41}$ aunque sí resulta interesante para evidenciar la presencia de élites urbanas en la ciudad durante la segunda mitad del siglo IV momento en el que se fecha su construcción. También los materiales de la gran necrópolis paleocristiana del Francolí en el suburbium de Tarraco pueden ser tomados como reflejo de la importancia de la ciudad durante

32 Para Darró ver A. López Mullor, X. Fierro Macia y A. Caixal Mata, "Ceràmica del segles IV al X procedent de les comarques de Barcelona", Contextos ceràmics d'època romana tardana i de l'alta edat mitjana (segles IV-X). Actes de la Taula Rodona organitzada a Barcelona els dies 6, 7 i 8 de novembre de 1996, ArqueoMediterrània, 2, Barcelona, 1997, pp. 59-82. Los materiales de La Solana se analizan en E. Barrassetas i Dunjó y R. Járrega i Domínguez, "La ceràmica trobada al jaciment de La Solana (Cubelles, Garraf)", Contextos ceràmics d'època romana tardana i de l'alta edat mitjana (segles IV-X). Actes de la Taula Rodona organitzada a Barcelona els dies 6, 7 i 8 de novembre de 1996, ArqueoMediterrània, 2, Barcelona, 1997, pp. 131-152.

33 C. Aguarod, Cerámica romana importada de cocina en la Tarraconense, Zaragoza, I99I, pp. 247, 252, 254, 255, 268, 277, 278, 283, 287, 288.

34 R. Járrega, Cerámicas finas tardorromanas y del Mediterráneo oriental en España. Estado de la cuestión, Anejos de AEspA, XI, Madrid, 1991, p. 22.

35 Hayes 58b, Hayes 59, Hayes 6I, Hayes 67 y Holwerda 1936 VI, 658.

36 Keay $X X V$ y Keay $X X X V$.

37 Keay XIIIA y Keay XIX.

38 Cfr. Macias, et alii, 1997, cit., pp. I53- 177.

39 TED'A (Taller-Escola d'Arqueologia), Un abocador del segle V d.C. en el Fòrum Provincial de Tàrraco, Memòries d'Excavació, 2, Tarragona, 1989, pp. 403-4l4 y pp. 205-246.

40 Tipologías identificadas y analizadas en C. Carreras y P. Berni, "Producció de vi i àmfores tardanes al NE de la Tarraconense", El vi a l'Antiguitat. Economia, Producció i Comerç al Mediterrani Occidental. Actes del II Col/loqui Internacional d'Arqueologia romana (Badalona, Maig 1998), Badalona, 1998, pp. 270-276.

4 I R. Mar, et alii, "El conjunto paleocristiano del Francolí en Tarragona. Nuevas aportaciones", Antiquité Tardive, 4, 1996, pp. 320-324. Cfr. también R. Cortés, "Problemas arqueológicos y de interpretación de la basílica y residencia suburbana del Parc Central (Tarragona)", Transformaciones en Hispania durante la Antigüedad tardía (s. IV-X). Newsletter, n4, marzo 200 I, p. 3. 
la segunda mitad del siglo IV y durante todo el siglo $V$ con personajes que se hacen enterrar en sarcófagos procedentes de los talleres italianos o del norte de África o cuyas sepulturas se cubren con preciosas laudae musivas ${ }^{42}$. Junto a estos dos elementos (uilla suburbana y necrópolis) se construye, a mediados del siglo $V$, una gran basílica funeraria dotada de un atrium, un mausoleo a los pies y una serie de edificios de carácter industrial ${ }^{43}$. También los vertederos excavados en distintos puntos de la ciudad permiten comprobar como durante todo el siglo V (y hasta el VII) se seguían importando productos de procedencia oriental y africana hecho que muestra la existencia de una población con recursos suficientes para pagar el consumo de estos materiales.

Una fuente excepcional para el conocimiento de la ciudad de Tarraco en el siglo $V$ es una carta escrita por Consencio a San Agustín y recogida como documento número II en el epistolario de éste último ${ }^{44}$. En este texto aparecen un buen número de personajes pertenecientes a las aristocracias de la ciudad o que se encontraban temporalmente en ella como el comes Asterio que se hallaba en la ciudad por circunstancias de carácter militar 45 (hecho que permite fechar la epístola en el año 420), un pariente suyo llamado Severo, su hija Severa además del obispo metropolitano, obispos de otras sedes y distintos personajes de la jerarquía eclesiástica. La residencia de estos individuos se halla en Tarraco como: el praetorium que es definido como domus del comes ${ }^{46}$. Pero además el protagonista de la historia, un monje llamado Fronto, cuenta que Asterio se desplaza en un cierto momento a una residencia fuera de Tarraco para participar en un banquete: Qui eadem die ad suburbanum pro- fectus iucunde quidem epulatus est... ${ }^{47}$ edificio que bien podría referirse a una de las uillae del ager tarraconensis que continuaban en funcionamiento a mediados del siglo $\mathrm{V}$ y donde la aristocracia urbana gozaba de sus momentos de otium. Una vez más se constata como ciudad y campo no son dos conceptos independientes y aislados sino que se trata de ámbitos frecuentados por los mismos protagonistas.

\section{Transformaciones arquitectónicas y funcionales de las uillae}

En un momento impreciso, variable según el edificio, pero que se podría situar hacia la segunda mitad del siglo $V$ se producen transformaciones que afectan tanto a la estructura arquitectónica como a la función original de las uillae.

El estudio de estas transformaciones resulta complejo dado que el cambio de función no implica grandes transformaciones arquitectónicas sino más bien reformas puntuales como muros de compartimentación, cisternas, repavimentaciones, etc. que, en la mayor parte de casos, son difíciles de fechar ya que raramente se cuenta con materiales que permitan situar cronológicamente el momento en que se producen.

En el sector central de la uilla de Els Munts y junto a las habitaciones que fueron destruidas por el incendio del 260-270 d. C. se instalan una prensa y varios dolia presumiblemente para la producción vinícola. No se tienen referencias estratigráficas que permitan precisar la cronología de esta instalación pero los investigadores proponen una fecha situada entre los siglos $\vee$ y $V I$ d. C. También en el edificio ter-

\footnotetext{
42 Una síntesis reciente sobre estos materiales se puede encontrar en: S. Vidal, "Escultura funerària", Del romà al romànic, I999, cit., pp. 215-225 y A. Chavarría, "Mosaics funeraris", Del romà al romànic, 1999, cit., pp. 301-304.

43 J. López i Vilar, "Un nuevo conjunto paleocristiano en las afueras de Tarraco”, Revista de Arqueología, I97, IX, I997, pp. 58-64.

44 Sancti Aureli Augustini Opera, Epistolae ex duobus codicibus nuper in lucem prolatae, J. Divjak (ed.), Corpus Scriptorum ecclesiaticorum latinorum, vol. LXXXVIII, I98I.

45 Ep. II, 7.

46 Ep. II, 8; I1, 12.

47 Ep. II, I3.
} 
mal se han individualizado muros tardíos de compartimentación apoyados sobre los mosaicos así como la construcción de varios depósitos, reformas que podrían estar relacionadas con la reutilización productiva del sector residencial. Este uso tardío se debe relacionar con la necrópolis descubierta en 1997 a unos 100 $\mathrm{m}$ al oeste del centro de la uilla (Lámina 2). Se trata de un conjunto funerario compuesto por unas 170 tumbas fundamentalmente en fosa aunque también hay algunas infantiles en ánfora y estructura de tegulae. A pesar de la ausencia de depósitos funerarios se ha podido fechar el origen de la necrópolis a mediados del siglo IV, cronología aportada por algunas ánforas ${ }^{48}$ y parece que continúa en uso a lo largo de los siglos V, VI y VII ${ }^{49}$. Seguramente la comunidad que se entierra en esta necrópolis haya de ser identificada con la población campesina que trabajaría el territorio asociado a la uilla y que reutilizaría sus estructuras para llevar a cabo nuevas actividades ya fuesen de tipo habitativo o vinculadas a la transformación de productos agrícolas. Es imposible, a partir de la evidencia arqueológica, determinar que habría sucedido con el dominus de esta residencia durante el periodo tardoantiguo, es decir, si existía todavía un gran propietario, el lugar en que vivía y dónde fue enterrado. Se hace difícil pensar que el propietario continuase habitando en una zona de la uilla (al menos de las estructuras que se conocen) dado el nuevo carácter rústico industrial que asumen muchos sectores, el hecho que parte de la estructura arquitectónica estaba en ruinas y la falta de materiales arqueológicos de cierta entidad de época tardía a excepción de la placa de tipo liriforme hallada durante las excavaciones de los años 60 con una cronología comprendida entre los siglos $\mathrm{VI}$ al $\mathrm{VIII}{ }^{50}$.
También en la uilla de La Rectoría (Pacs) se produce la reutilización de una de las habitaciones del sector residencial como espacio rústico, como muestran los tres dolia que se encastran en el mosaico pavimental. En este caso la superficie conocida de la uilla es muy reducida y las intervenciones arqueológicas son antiguas hecho que imposibilita determinar el alcance de la reutilización y mucho menos su cronología ${ }^{5}$.

Aunque los investigadores alemanes consideran que el abandono de Centcelles se produce a inicios del siglo $\vee$ existen algunos vestigios que indican un uso o reutilización tardía del complejo termal como la repavimentación de una habitación con opus signinum (bajo el cual apareció un fragmento de mosaico de similar estilo al de la cúpula) o la compartimentación de algunas estancias. Aunque no es posible precisar la cronología de estas reformas ya se ha aludido anteriormente a la existencia de material cerámico del siglo $V$ en el yacimiento y no hay que olvidar el hallazgo de un triens de oro de Recesvinto (siglo VII) que parecen abogar por la continuidad de frecuentación de esta parte de la uilla hasta bien entrada la antigüedad tardía.

También en el conjunto termal de Mas dels Frares en Constantí se produce, en un momento indeterminado de la antigüedad tardía, un cambio en la forma y función de sus estructuras que pasan a ser utilizadas para actividades de carácter productivo ${ }^{52}$.

En Paretdelgada, la construcción de una iglesia y unas estructuras de carácter monástico a partir del edificio de una uilla ha hecho pensar que en época tardoantigua parte del edificio se hubiese convertido en espacio de culto a raíz

\footnotetext{
48 Keay XXIII y Keay XXVB, cfr. M. García, J. M. Macias y M. Teixell, "Necròpoli de la vil·la dels Munts", Del romà al romànic, 1999, cit., pp. 278-279.

49 Un análisis de ésta y otras necrópolis de la Península Ibérica en relación a las transformaciones de las uillae en A. Chavarría, “Villa y necrópolis en Hispania durante la Antigüedad tardía", Bulletin de l'Association pour l'Antiquité tardive, 9 (e.p.).

50 P. de Palol, "Fíbulas y broches de cinturón de época visigoda en Cataluña", Archivo Español de Arqueología, 78, 1950, pp. 73-97.

51 Gorges, 1979, cit., p. 49 y 212 y A. Balil, “La villa romana de Pacs (Penedès, Barcelona)", Boletín del Seminario de Estudios de Arte y Arqueología, Valladolid, 1987, pp. 181-189.

52 R. Cortés, et alii, "Resultats de la primera campanya d'excavacions del Mas dels Frares de Constantí (juliol, I989)", Butlletí Arqueològic, V, 13, 1991, pp. 69-82; Anuari d'intervencions arqueològiques a Catalunya, 1993, cit., p. 267.
} 
de la existencia de un oratorio privado, aunque a pesar de la superposición de estructuras faltan evidencias que permitan fundamentar esta hipótesis ${ }^{53}$. La dificultad que supone determinar la cronología de los niveles arqueológicos de los siglos $\mathrm{V}$ al VIII y la inexistencia de fuentes textuales impide -como sucede habitualmente en este tipo de casos- establecer la fecha de abandono del edificio romano (si es que fue abandonado) y la datación original del edificio de culto y por tanto, poder evaluar si existe algún tipo de continuidad entre ambas estructuras ${ }^{54}$.

Otro fenómeno observado en las uillae del ager tarraconensis durante la antigüedad tardía es el abandono de habitaciones o edificios y su reutilización como espacio funerario. En Cal·lípolis se halló una necrópolis con sepulturas que testimonian dos fases de uso de este conjunto. Una primera fase con tumbas de tegulae e imbrices excavadas en niveles del siglo III y orientadas en dirección norte-sur y, a un nivel superior, una segunda fase con sepulturas construidas con losas de piedra y orientadas oeste-este. En otro sector de la uilla estructuras abandonadas también son aprovechadas como necrópolis con sepulturas orientadas en función de las estructuras arquitectónicas preexistentes. La cronología viene dada por una tumba infantil en ánfora de procedencia oriental fechada entre los siglos IV y VII ${ }^{55}$. Idéntico fenómeno se observa en Darró donde, en un momento tardío, parte de la zona rústica se abandona y es ocupada por numerosas sepulturas de tegulae, ánforas, losas y fosa ${ }^{56}$. Tanto en Cal·lípolis como en Darró parece que la uilla sigue en funcionamiento hasta el siglo VI. También la parte residencial de la uilla de Els Hospitals fue abandonada en el siglo $V$ y utilizada como necrópolis con tumbas de tegulae, losas y fosa que siguen la orientación de las estructuras arquitectónicas ${ }^{57}$. Un último ejemplo objeto de publicación reciente es la Llosa (Cambrils) donde, una vez abandonadas las estructuras, éstas se reutilizan para instalar varias sepulturas. En una habitación fue hallada una sepultura infantil dentro de una ánfora local y una sepultura en fosa que contenía un esqueleto femenino con un interesante depósito funerario compuesto por un pendiente, una placa de cinturón cuadrangular con hebilla arriñonada, tres brazaletes, un collar con bolas de pasta vítrea y una posible caja de bronce (Lámina 4). La tumba cortaba un estrato del siglo $V$ y la tipología de los materiales apunta a una cronología general de época tardorromana ${ }^{58}$.

\section{INTERPRETACIÓN}

El análisis de algunos establecimientos rurales situados en el territorio de otras ciudades de la Tarraconensis pone de manifiesto como las transformaciones y cambios de función analizados son un fenómeno generalizado en un importante número de yacimientos ${ }^{59}$. Quizás

\footnotetext{
53 Guitert, 1936, cit.

54 Esta problemática ha sido tratada recientemente en distintas áreas. Entre los trabajos más significativos cabe citar a P. A. Février, "La marque de l'Antiquité tardive dans le paysage religieux médieval de la Provence antique", en M. Fixot. y E. Zadora Rio (eds.), L'environnement des églises et la topographie religieuse des campagnes médiévales: Actes du llle congrès international d'archéologie médiévale, (Aix en Provence, 1989), JAf, 46, París, 1994, pp. 27-35; J. Percival, "Villas and Monasteries in Late Roman Gaul", Journal of Ecclesiastical History, vol. 48 (I), 1997, pp. I-2I; T. Bell, "Churches on Roman Buildings: Christian Associations and Roman Masonry in Anglo-Saxon England", Medieval Archaeology, XLII, 1998, pp. I- I8; G. Cantino Wataghin, "... ut haec aedes Christo Domino in Ecclesiam consecretur. II riuso christiano di edifici antichi tra tarda antichità e alto medioevo", XLVI Sett. St. CISAM, t. 2, Spoleto, 1999, pp. 673-749.

55 Macias y Tuset, 1996, cit.

56 López y Fierro, 1991, cit.

57 M. García, J. M. Macias e I. Teixell, "Món funerari del territori de Tarraco", Del romà al romànic, 1999, cit., p. 276.

58 E. Riu, J. J. Menchon y J. Massó, "Bronzes de la vil·la de la Llosa", Del romà al romànic, 1999, cit., pp. 315-316.

59 Un amplio análisis de estas transformaciones en A. Chavarría Arnau, "Transformaciones arquitectónicas de los establecimientos rurales en el nordeste de la Tarraconensis durante la antigüedad tardía". Butlletí de la Reial Acadèmia Catalana de Belles Arts de Sant Jordi, Barcelona, 1996, pp. 165-202 y Ead., "Els establiments rurals del llevant de la Tarraconesa durant l'antiguitat tardana: transformacions arquitectòniques i funcionals", Annals de l'Institut d'Estudis Gironins, XXXIX, 1998, pp. 9-30. Una primera aproximación, de carácter básicamente bibliográfico, sobre estas transformaciones en Hispania (tema de mi tesis doctoral) en Ead., "Novedades bibliográficas sobre villae romanas en Hispania durante la Antigüedad tardía (1990-1999)", Bulletin de l'Association pour l'Antiquité tardive, 8, 1999, pp. 57-67.
} 
donde este proceso es más evidente es la uilla de Torre Llauder (Mataró) en la que varias estancias del sector residencial se utilizan para encastrar dolia y construir depósitos, reformas que se fechan en la segunda mitad del siglo IV $\circ$ ya en el $V$ y que se mantienen en funcionamiento como mínimo hasta el siglo VI ${ }^{60}$. En la uilla de Vilauba (Camós, Girona), y tras un incendio fechado a finales del siglo III, se lleva a cabo una gran reconstrucción consistente en la supresión de los ambientes residenciales, la edificación de nuevos ámbitos, la generalización de pavimentos de opus signinum, y la construcción de varios depósitos y prensas, elementos que evidencian la conversión del edificio en centro dedicado a la producción. Su abandono se fecha a partir del siglo VI o incluso VII ${ }^{61}$. En establecimientos como La Font del Vilar (Avinyonet de Puigventós, Figueres), L'Aiguacuit (Terrassa), Sant Boi de Llobregat o Can Terrés (La Garriga) se inutilizan y reforman sus estructuras instalándose nuevos pavimentos y prensas, cambiando la organización y dimensiones de los espacios, construyéndose depósitos, etc. Estos elementos demuestran la anulación de su función residencial primitiva y su posterior reutilización con carácter rústico ${ }^{62}$.

Los investigadores que han estudiado estas transformaciones en las uillae de la Tarraconensis y de otras provincias del Imperio las han interpretado de modo diverso relacionándolas con el asentamiento de poblaciones bárbaras en los edificios ${ }^{63}$, con una crisis económica y cul- tural de los propietarios ${ }^{64}$ o con cambios en el sistema de vida de la población ${ }^{65}$ viendo en el nuevo carácter "rural" de las uillae un precedente de la organización rural característica del medioevo ${ }^{66}$.

Resulta complejo proponer una única explicación para estas transformaciones ya que en los motivos que llevaron al cambio de función de antiguos hábitats o residencias rurales intervinieron múltiples factores de carácter geográfico, económico, político, social y cultural. Sin embargo hay que tener en cuenta que las interpretaciones citadas asumen, por lo general, que los propietarios de las uillae continuaban viviendo en estos edificios hecho que, en un buen número de casos, parece poco probable. En muchos de los edificios analizados la superficie dedicada a residencia se reduce de manera muy importante $y$ a veces incluso se encontraba en avanzado estado de ruina -como en Els Muntsy es difícil sostener que el propietario continuase viviendo en ellos y por tanto defender (al menos para el momento en que se producen las transformaciones, esto es, siglos $\mathrm{V}$ y VI) la hipótesis de una crisis económica y cambio cultural de estos individuos. Tampoco han aparecido en estas uillae materiales que permitan pensar que las transformaciones fueron debidas al asentamiento de población distinta a la hispanorromana hipótesis tampoco avalada por la documentación histórico-arqueológica que no señala para el levante de la provincia Tarraconensis una presencia "bárbara" destacable ${ }^{67}$.

60 J. F. Clariana y M. Prevosti, “Un exemple de ruralització a l'antiguitat tardana: la vil·la de Torre Llauder", III Reunió d’Arqueologia Cristiana Hispànica (Maó, 1988), Barcelona, 1994, pp. 117-126.

61 Cfr. como más reciente P. Castanyer i Masoliver y J. Tremoleda i Trilla, La villla romana de Vilauba. Un exemple de l'ocupació i explotació romana del territori a la comarca del Pla de l'Estany, Girona, 1999.

62 El estudio y bibliografía sobre estos yacimientos en Chavarría, 1996 y 1998, cit.

63 Clariana y Prevosti, 1994, cit., p. 125.

64 Clariana y Prevosti, 1994, cit., p. 125

65 Lewit, 1991, cit., pp. 44-46.

66 R. Járrega, "El poblamiento rural en el este de la Tarraconense en época Teodosiana”, Congreso Internacional La España de Teodosio, vol. 2, 1997, pp. 533-542.

67 Para el asentamiento visigodo en la Península ver con carácter general G. Ripoll e I. Velázquez, La Hispania visigoda. Del rey Ataúlfo a Don Rodrigo, Historia de España (Historia 16-Temas de Hoy), 6, Madrid, 1995. El análisis del asentamiento a partir de la documentación arqueológica y, fundamentalmente del estudio de las necrópolis se debe básicamente a G. Ripoll. Cfr. como trabajo más reciente sobre esta problemática G. Ripoll, "The arrival of the visigoths in Hispania: population problems and the process of acculturation", W. Pohl y H. Reimitz (eds.), Strategies of Distinction. The construction of Ethnic Communities, 300-800, Brill, Leiden-BostonKöln, 1998, pp. 153-187. 
Posiblemente se tenga que pensar ${ }^{68}$ en un traslado de los propietarios a otras residencias y el aprovechamiento de las antiguas para las nuevas funciones que aquí se han analizado. Quizás también haya que relacionar este traslado con cambios en el sistema de la propiedad y la explotación agraria y, más concretamente, con el fenómeno de concentración de propiedades que se documenta de manera generalizada en todo el Imperio durante la antigüedad tardía 69. Esta acumulación de propiedades con sus correspondientes edificios por parte de determinados possessores haría que aquellas construcciones que una vez habían servido como residencia dejasen de ejercer esta función y fuesen utilizadas para otras actividades vinculadas a la explotación de la propiedad (industrias, talleres, almacenes, establos) o a sus trabajadores (hábitats o necrópolis).

Quedan abiertas una serie de cuestiones. Las necrópolis rurales parecen corresponder a los trabajadores que explotaban el territorio dependiente de las uillae pero desconocemos donde vivían esta población y tampoco sabemos donde residían los propietarios de estas tierras cuando las uillae pierden su función residencial. Algunos indicios materiales permiten pensar que, en algunos casos los campesinos viviesen en las mismas uillae aprovechando sus estructuras y conformando las "formas de hábitat de carácter marginal" identificadas en algunos edificios. También es posible que habitasen cerca de la uilla en edificios construidos en madera, adobe y otros materiales que no hayan sido detectados por los arqueólogos.
Más problemático es determinar donde se encontraban los propietarios de estas explotaciones. Como se ha visto, las transformaciones arquitectónicas y cambios funcionales que experimentan las uillae provocan la desintegración de estos edificios haciendo desaparecer su carácter aristocrático a partir de mediados de siglo $\checkmark$. La ausencia de mausoleos o sepulturas privilegiadas en las uillae y sus proximidades no permiten ubicar el lugar de enterramiento del dominus y determinar por tanto si habitaba en estos edificios. Tampoco en la ciudad han aparecido vestigios de carácter estructural que permitan detectar la presencia de una aristocracia destacable en la ciudad del siglo $V$ en adelante ${ }^{70}$. La parte baja de Tarraco se abandona a partir del s. $V$ y parece que la población se concentra en la parte alta que se constituye en recinto fortificado. ¿Hay que pensar en la desaparición de las aristocracias romanas? ¿O bien en cambios en su sistema de vida y en el modo en que se presentaban y que las hace irreconocibles al registro arqueológico?

El hecho que el único elemento remarcable del paisaje urbano (y sobre todo suburbano) sean las construcciones cristianas como refleja tanto la documentación arqueológica como las fuentes textuales (y particularmente la carta de Consencio ya mencionada) muestra la gran importancia que tenía la Iglesia desde el siglo IV y fundamentalmente a partir del $\mathrm{V}$ llegándose a convertir en uno de los poderes más influyentes y significativos de la Tarraco tardoantigua y evidentemente de su territorium dada la importancia creciente del patrimonio eclesiástico.

\footnotetext{
68 Como ya apuntaba Percival, 1976, cit., p. 125.

69 Un análisis extenso de este proceso en D. Vera, "Forme e funzione della rendita fondiaria nella tarda antichità", SRIT, Roma-Bari, 1986, pp. 367-447; Íd., D. Vera, "Dalla "villa perfecta" alla villa di Palladio: sulle transformazioni del sistema agrario in Italia fra principato e dominato", Athenaeum, 83.1, 1995, pp. I89-212 y 83.2, 1995, pp. 33I-356 y C. Wickham, "From Ancient World to Feudalism", Past and Present, I03, 1984, pp. 3-36.

70 De hecho tampoco tenemos constancia del hallazgo de ninguna gran residencia urbana para el siglo IV. Cfr. para esta época Macias, 1999, cit., pp. 305-318.
} 


\section{APÉNDICE DE UILLAE ANALIZADAS EN EL TEXTO *}

\section{Darró (Vilanova i la Geltrú)}

- Descubierta en 1880 con motivo de la construcción de la línia de ferrocarril. Trabajos arqueológicos en la década de los años cincuenta ( $F$. Ferrer Soler y A. Arribas) y ochenta (A. López y $X$. Fierro).

- Edificio de carácter residencial, ámbitos con función productiva y dos hornos para la fabricación de cerámica. El edificio residencial es de planta rectangular con galería de fachada y estancias articuladas a partir de varios pasillos. Destaca una sala dotada de una cabecera pentagonal en su extremo oeste. Pavimentos de opus signinum, cal y mosaico.

- Se construye en el s. II d. C. y es completamente reformado entre la segunda mitad del s. III y primera mitad del IV. Hacia el 350 se realizan nuevas reformas. Compartimentación de la estructura interior, construcción de la cabecera pentagonal precedida de un escalón y una plataforma. Entre finales del s. IV y la primera mitad del s. $V$ se realizan pequeñas modificaciones como la instalación de nuevos pavimentos de opus signinum y cal y el cambio de acceso de algunas habitaciones. El abandono del establecimiento se fecha a finales del s. $V$ d.C. o VI a partir del material cerámico. A partir del s. $V$ parte de la zona rústica es ocupada por sepulturas de tegulae, ánfora, losas y fosa.

- Sigillatas africanas D, cerámica de cocina africana, sigillata sudgálica, cerámicas grises hechas a torno lento y monedas de los ss. III y IV.

- A. Arribas, 1959: "El poblado ibérico y la villa romana de Adarró (Villanueva y la Geltrú)", Ampurias, XXl, pp. 323-329; A. López y J. Fierro, 1990: "La época romana en Darró (Vilanova i la Geltrú, Barcelona", ETF (arqueol), t. 3, pp. 203254; A. López y X. Fierro, "Un conjunto cerámico cerrado, del siglo $\vee$ d.C., hallado en Darró, Vilanova i la Geltrú, Barcelona", ETF (arqueol), t. 6, 1994, pp. 343-364; A. López Mullor, X. Fierro Macia y A. Caixal Mata, 1997: "Ceràmica del segles IV al $X$ procedent de les comarques de
Barcelona", Contextos ceràmics d'època romana tardana i de l'alta edat mitjana (segles IV-X), ArqueoMediterrània, núm. 2, Barcelona, pp. 59-82.

\section{Castell de Cubelles (Garraf)}

- Conocida desde el s. XIX y excavada en los años noventa con motivo de la restauración de este conjunto arquitectónico (Servei del Patrimoni Arquitectònic de la Diputació de Barcelona).

- Habitaciones, muros, fragmentos de mosaicos, dolia, ánforas, canalizaciones y material cerámico vinculado a la existencia de un establecimiento rural con función rústica y residencial.

- Materiales que van desde época republicana hasta el s. V. Numerosas reformas en época tardía como inutilización de mosaicos, compartimentación de los espacios, etc.

- A. López, X. Fierro y A. Caixal, 1997: "Un nou jaciment a l'ager de Tarraco: la vil·la romana del Castell de Cubelles", Hispania i Roma. D'August a Carlemany, Annals de I'Institut d'Estudis Gironins, vol. XXXVII, Girona, p. 853-873; A. López Mullor, X. Fierro Macia y A. Caixal Mata, 1997: "Ceràmica del segles IV al X procedent de les comarques de Barcelona", Contextos ceràmics d'època romana tardana i de l'alta edat mitjana (segles IV-X), ArqueoMediterrània, núm. 2, Barcelona, pp. 59-82.

\section{La Solana (Cubelles, El Garraf)}

- Objeto de intervenciones arqueológicas con motivo de la construcción de la autopista A- 16.

- Estructuras arquitectónicas de un establecimiento rural dedicado producción de vino y una necrópolis.

- Los materiales cerámicos de importación y varios objetos metálicos proporcionan una cronología situada entre los siglos $\bigvee$ y VII.

- J. Morer, A. Rigo y E. Barrasetas, 1997: "Les intervencions arqueológiques a l'autopista A- 16: valo-

* Los apartados se refieren a: historia de la investigación, descripción, evolución, materiales tardíos y bibliografía. 
ració de conjunt)", Tribuna d'Arqueología 199697, pp. 67-98; E. Barrassetas i Dunjó y R. Járrega i Domínguez, 1997: "La ceràmica trobada al jaciment de La Solana (Cubelles, Garraf)", Contextos ceràmics d'època romana tardana i de l'alta edat mitjana (segles IV-X), ArqueoMediterrània, 2, Barcelona, pp. |3|-|52.

\section{La Rectoria (Pacs del Penedès, Alt Penedès)}

- Descubrimiento y excavaciones en 1926 (J. Colominas).

- Muros y tres mosaicos, dos de ellos polícromos con decoración geométrica y floral y uno monócromo de teselas blancas. Entre el material recuperado destacan varios recipientes de bronce.

- La cronología de uno de los mosaicos y el material recuperado indica como durante el s. IV el establecimiento conserva su función residencial. En un momento posterior se produce la reutilización de al menos una de las estancias cuyo mosaico es parcialmente destruido para encastrar tres dolia.

- J. G. Gorges, 1979: Les villas hispano-romaines. Inventaire et problématique archéologiques, París, p. 49 y 212; A. Balil, 1987: "La villa romana de Pacs (Penedès, Barcelona)", BSEAA, pp. |8|- 189.

\section{El Moro (Torredembarra)}

- Prospecciones de M. Berges en los años sesenta y excavaciones en los años ochenta.

- Conjunto termal, edificio residencial con pavimentos de signinum teselado y sector rústico.

- El sector termal funciona entre los ss. I y III y posteriormente pasa a ser utilizado para otras actividades quizás de tipo productivo como muestran varias reformas estructurales y la construcción de un depósito sobre uno de los pavimentos.

- Anuari d'intervencions arqueològiques a Catalunya. Època romana-Antiguitat tardana. Campanyes 1982-1989, Barcelona, 1993, p. 266.

- E. Terré, 1987: "La vil·la romana de "El Moro" (Torredembarra): un exemple de poblament rural al Camp de Tarragona", Jomades Intemacionals d'Arqueologia romana, Granollers, pp. 217-224.

\section{Els Munts (Altafulla)}

- El conocimiento de estas estructuras se remonta al s. XVI cuando aparece en el Llibre de les grandeses de Tarragona de LI. Pons d'lcard. A principios de siglo se descubre un conjunto de monedas estudiado en 1950 por F. Mateu Llopis. El primero en estudiar el yacimiento científicamente fue P. Bosch Gimpera en 1925. En 1949 se inician las excavaciones (J. Sánchez Real y Serra Vilaró) y a partir de 1967 se hace cargo M. Berges, quién realiza varias excavaciones. Reestudio del conjunto termal en 1993 (J. López). Nuevas intervenciones desde 1995 (F. Tarrats).

- Conjunto de estructuras muy extenso con un núcleo principal que comprende un rectángulo de $200 \times 100 \mathrm{~m}$. En el extremo noroeste del yacimiento hay grandes cisternas, en la parte superior del núcleo principal se han documentado varios ámbitos con instalación de hipocausto pertenecientes a un posible conjunto termal y otras habitaciones algunas con pavimentos musivos y otras con opus signinum. En el sector norte es posible identificar una amplia estructura semicircular (que ya aparece en los planos de Berges) sin excavar que podría estar en relación con algún ámbito de representación de la uilla. En esa misma zona destaca un gran espacio rectangular rodeado por un pasillo con pavimentos musivos. El centro de las estructuras está ocupado por un pasillo o ambulacro con forma de L que da acceso por un lado a numerosos ámbitos pavimentados con mosaicos y muros revestidos con pinturas y por el otro lado, se comunicaba con un jardín. En la parte inferior se encuentran las Ilamadas "termas inferiores" compuestas por estancias pavimentadas con mosaicos, muros con aplacados de mármol, grandes piscinas, etc. y parcialmente en la playa otras estructuras denominadas "termas marinas".

- Las primeras estructuras se construyen en el s. I d. C. Rehechas y ampliadas a mediados del s. II cuando la uilla recibe un importante aparato decorativo. El propietario de la uilla durante esta fase se identifica con Caius Valerius Avitus miembro de la administración provincial de la Tarraconensis, vinculación establecida gracias al hallazgo de un sello de bronce y de una inscripción pintada donde se conmemora la construcción de una cisterna. Importante nivel de incendio y destrucción en el sector residencial fechado en la década del 260-270. Tras el incendio este sector no fue jamás reconstruido y parte del sector residencial fue utilizado sólo de manera residual para actividades de carácter productivo. Durante el s. IV tienen lugar diversas obras en las llamadas "termas inferiores" que son objeto de una importante monumentalización arqui- 
tectónica con la creación de nuevos espacios y programa decorativo. J. López fecha esta monumentalización en la segunda mitad del s. IV basándose en la existencia de un fragmento de cerámica sigillata usado como material de construcción de un canal, el hallazgo de un conjunto de cuatro monedas del 350 bajo uno de los pavimentos y el estilo de los mosaicos.

- Necrópolis situada a unos 100 m del centro de la uilla. Se instala sobre un área destinada a anteriormente a almacenamiento abandonada hacia finales del s. III. Esta constituida por unas 170 sepulturas de fosa y ánfora. Cronología situada entre los ss. IV y VII.

- Además de varios conjuntos de monedas fechados en la segunda mitad del s. III se documentaron numerosas monedas del s. IV en la zona de las termas inferiores. Como material más tardío destaca una placa de cinturón de perfil liriforme fechada entre los ss. VI al VIII. No se han publicado estudios sobre el material cerámico.

- M. Berges, 1969-70: "Informe sobre Els Munts", Boletín Arqueológico, IV, 4, pp. I40-I50; M. Berges, 1977: "Nuevo informe sobre Els Munts", Estudis Altafullencs, I, pp. 27-47; J. López, 1993: "Les termes inferiors de la vil.la romana dels Munts", Utilització de l'aigua a les ciutats romanes, Documents d'Arqueologia Clàsica, 0, Tarragona, pp. 56-79; F. Tarrats, E. Ramon y J. M. Macias, Noves intervencions a la vil·la romana d'Els Munts (Altafulla, Tarragonès), Tribuna d'Arqueología 1996-97, 1997, pp. 35-56; F. Tarrats, et alii, 1998: "Excavacions a l'àrea residencial de la vil·la romana dels Munts (Altafulla, Tarragonès), Empúries, 51, pp. 197-225.

\section{Centcelles (Constantí)}

- Aunque su identificación como construcción romana es muy antigua el descubrimiento de los mosaicos que revisten la cúpula de una de las habitaciones no se produce hasta 1877. A partir de ese momento se iniciaron una serie de estudios sobre los mosaicos, las pinturas y el edificio en sí entre los que destacan los de $F$. Albiñana y A. Bofarull ( 1897$)$, B. Hernández Sanahuja (|883), J. Puig i Cadafalch (|9||), LI. Domènech i Montaner (192 I), J. Gudiol (1925) F. Camprubí (1953), P. de Palol (I 954 y | 96 |). A partir de 1959 miembros del Instituto Arqueológico Alemán y la Deutsches Gemeinschaft bajo la dirección de $H$. Schlunk y T. Hauschild se hacen cargo de la excavación, estudio y res- tauración del monumento y publican una serie de informes sobre algunos materiales y varias monografías centradas en el análisis e interpretación de los mosaicos y de la sala que decoraban (Schlunk, 1988 ; Hauschild-Arbeiter, 1993). Se interpreta como un mausoleo, posiblemente del emperador Constante asesinado en el año 350 en el sur de la Gallia, intepretación discutida por J. Arce (1994) quien propone vincularlo con otro individuo, quizás un miembro de la alta jerarquía eclesiástica.

- Bloque arquitectónico rectangular de unos 90 $m$ de largo del que se diferencia una zona central compuesta por tres habitaciones, dos de planta centrada una circular y cubierta mediante una cúpula y otro ámbito cuadrilobulado, y una de planta rectangular y dotada con una exedra. Al este del bloque se descubrieron varios ámbitos muy arrasados. Al oeste existía un conjunto termal perteneciente a dos fases cronológicas distintas. Al sur de todas estas estructuras se han realizado prospecciones que han descubierto cimientos, canalizaciones, y dolia, pertenecientes a ámbitos de carácter productivo de cronología anterior.

El programa decorativo de la estancia de planta centralizada y el hecho que esté dotada de una cripta ha hecho suponer a muchos investigadores que este ámbito fuese un mausoleo, posiblemente imperial, interpretación que ha condicionado la interpretación del conjunto y su cronología. La falta de excavaciones extensivas (conocemos sólo una parte de un conjunto residencial posiblemente mucho más amplio) y la escasez de materiales publicados impide realizar un análisis profundo sobre su cronología y evolución, especialmente por lo que se refiere a las fases más tardías. Según los investigadores alemanes la mayor parte de las estructuras de la uilla de Centcelles se contruye hacia la segunda mitad del s. II d. C. en un espacio previamente ocupado por estructuras de carácter rústico. En el s. IV se llevaría a cabo la construcción de un nuevo conjunto termal y la decoración de la estancia de la cúpula con mosaicos y pinturas y su transformación como mausoleo.

- A partir del s. IX aparece citado en distintos textos como ecclesia Sent Seleso / ecclesia de Centumcellis.

- Gran cantidad de monedas con cronología comprendida entre mediados del s. III e inicios del $\checkmark$ además de un triens de Recesvinto. Entre la poca cerámica que ha podido ser estudiada se 
han reconocido piezas de cocina y sigillata africana fechadas en la primera mitad del s. $V$.

- La bibliografía es amplísima. cf. H. Schlunk, 1988: Die Mosaikkupel von Centcelles, 2 vols., Maguncia; T. Hauschild y A. Arbeiter, 1993: La vil·la romana de Centcelles, Barcelona, ambos con bibliografía anterior. Entre los trabajos más recientes of. J. Arce, 1994: "Constantinopla, Tarraco y Centcelles", Butlletí Arqueològic, V, I6, Tarragona, p. I47165 y R. Warland, 1994: "Status und Formular in der Räpresentation der Spätantiken Führungsschicht", Römische Mitteilungen DAI, pp. 175-20I.

\section{Mas Serapi (Constantí)}

- Muros, fragmentos de pavimentos de opus signinum y mosaicos, estucos y cerámica que muestran la existencia de un establecimiento rural.

- El material cerámico muestra que se encontraba en uso durante la antigüedad tardía.

- J. G. Gorges, 1979: Les villas hispano-romaines. Inventaire et problématique archéologiques, París, pp. 412-13.

\section{Mas dels Frares (Constantí)}

- Gorges recoge en 1979 algunas noticias sobre este yacimiento que fue objeto de intervenciones en 1989 y 199| (R. Cortés).

- Conjunto termal.

- Ocupación comprendida entre los ss. I d. C. y el V-VI aunque a partir del s. IV se produce una reestructuración del edificio que pasa a ser utilizado para actividades de tipo rústico.

- R. Cortés, et alii, "Resultats de la primera campanya d'excavacions del Mas dels Frares de Constantí (juliol, 1989)", Butlletí Arqueològic, V, 13, 1991, pp. 69-82; J. Massó, Notes per l'estudi de Constantí a l'antiguitat, Centre d'Estudis de Constantí, 1990; Anuari d'intervencions arqueològiques a Catalunya, 1993, p. 267; L.A.U.T., 1993: "Mas dels Frares (Constantî)", Utilització de l'aigua a les ciutats romanes, Documents d'Arqueologia Clàsica, 0, Tarragona, pp. 100-103.

\section{Ermita de Sant Llorenç (Constantí)}

- Muros, fragmentos de pavimentos de opus signinum y cerámica pertenecientes a un estable- cimiento rural en relación a este edifico de culto muy próximo al yacimiento de Mas dels Frares.

- Papiol, 1973-74: "Noticias sobre hallazgos romanos en el término de Constantî", Boletín Arqueológico, V, I2I-124, pp. 250-256.

\section{Mas Pórpores (Reus)}

- Establecimiento rural con un sector residencial con habitaciones dotadas de sistema de hipocausto, pavimentos musivos y estucos y un sector productivo con varios hornos para la producción de material cerámico y depósitos. Junto a esta uilla se han excavado seis sepulturas de tegulae, losas de piedra, fosa y un pequeño sarcófago monolítico.

- Material cerámico y numismático del s. IV.

- M. Carreras, 1945: "Los hallazgos arqueológicos de Pórporas (Reus)", Boletín Arqueológico, III, I2. pp. 82-91.

\section{Els Antigons (Reus)}

- Establecimiento rural con sector rústico (hornos) y sector residencial del que se ha recuperado un interesante conjunto escultórico de temática dionisíaca de los ss. II-III que quizás decorase la uilla del s. IV. Se menciona la existencia de una necrópolis aunque no se precisa si ese encontraba cerca de la uilla o reutilizando sus estructuras.

- R. Capdevila y M. Massó, 1976-77: “Trabajos de salvamento de la villa romana de 'Els Antígons'Reus", Boletín Arqueológico, IV, pp. 312-313; G. Munilla, 1979-80: "Una estatua representando a la diosa Cibeles hallada en la villa romana de "Els Antigons"', Pyrenae, I5-16, p. 277 y sig.; E. M. Koppel, 1995: "La decoración escultórica de las uillae romanas en Hispania", en J. M. Noguera Celdrán (coord.), Poblamiento rural romano en el sureste de Hispania, Actas de las Jornadas celebradas en Jumilla del 8 al I I de noviembre de 1993, Murcia, pp. 46-47.

\section{Els Hospitals (El Morell)}

- Descubierta y objeto de intervenciones en los años noventa (CODEX).

- Sector residencial de un establecimiento rural dotado de conjunto termal. 
- Cronología situada entre época tardorrepublicana y el siglo $\vee$. A lo largo del s. IV y el $\bigvee$ sufre varias reformas importantes. A partir de la segunda mitad del s. $V$ será reutilizada como necrópolis con sepulturas de tegulae, losas y fosa.

- Abundante material cerámico de importanción africana (sigillatas y cerámica común) de los ss. IV y primer cuarto del $V$, ánforas africanas y béticas y cerámica común local.

- J. M. Macias, et alii, 1997: "Nous contextes ceràmics del segle IV i inicis del $\mathrm{V}$ en la provincia de Tarragona", Contextos ceràmics d'època romana tardana i de l'alta edat mitjana (segles IV-X), Arqueomediterrània, 2, Barcelona, pp. I53-I77.

\section{Paretdelgada (La Selva del Camp)}

- Descubierta durante las obras de reconstrucción de una ermita.

- Conjunto de estancias de forma cuadrangular, ocho de ellas pavimentadas con mosaicos, articuladas a partir de un peristilo central. Conjunto de esculturas en mármol y bronce.

- Cronología situada entre los ss. I y IV d.C. La coincidencia que existe entre la ermita y las estructuras preexistentes se ha considerado como un indicio de que el edificio de culto hubiera sido originalmente un antiguo oratorium. Se hace referencia a marcas de incendio en los mosaicos pero sin aportar dataciones al respecto.

- Gorges hace referencia a monedas del s. IV d.C. Interesante placa de bronce rectangular de unos $20 \mathrm{~cm}$ con decoración figurada repujada de cronología indeterminada.

- J. Guitert, 1936:"Descubriments romans a Pared Delgada", Boletín Arqueológico, III, 5, pp. |37-|4I; J. Sánchez Real, 1951: "Los mosaicos romanos de Pared Delgada", Boletín Arqueológico, III, pp. 106-109; A. García y Bellido, 1952: "Una placa de bronce repujado de la villa 'Pared delgada"', AEspA, XXV, pp. 4I0 4I2.

\section{Cal·lípolis (Vila-Seca)}

- Descubierta en 1955 cuando se exhuma el mosaico con representaciones de peces que pavimentaba una estancia de un conjunto termal. Durante los años 60 y 70 gran parte del establecimiento fue destruido debido a la expnasión urbanística. A inicios de los años 90 se realizan nuevas campañas a cargo del equipo CODEX.

- Establecimiento rural dotado de un sector residencial del que se ha excavado básicamente el conjunto termal e instalaciones de función productiva. La zona rústica está constituida por ámbitos amplios, depósitos, almacenes y se ha descubierto una pieza identificada como contrapeso de una prensa de vino y/o aceite.

- El conjunto termal se construye en época altoimperial y objeto de distintas reformas en el siglo IV y V. Su abandono se sitúa en torno al s. VI. Hacia el s. III o IV se abandonan algunas dependencias del sector rústico y se reutilizan como espacio funerario con tumbas de tegulae y losas.

- J. M. Macias y F. Tuset, 1996: "Excavacions arqueològiques a la vil·la romana de Cal·lípolis (VilaSeca, Tarragona)", Tribuna d'Arqueologia 19941995, pp. I|3-121; M. García, J. M. Macías e I. Teixell, 1999: "Món funerari del territori de Tarraco", Del romà al romànic, p. 276.

\section{La Llosa (Cambrils)}

- Descubierta de modo fortuito en 1980 y objeto de distintas intervenciones excavaciones (J. Massó y M. Magriñà y CODEX).

- Establecimiento organizado en varios edificios de los cuales el mejor conocido es el situado en la zona meridional. Ámbitos de forma cuadrangular algunos pavimentados con opus signinum y varios depósitos. Se interpreta como un establecimiento destinado a la producción de salazones aunque no se han hallado restos ictiológicos ni utillaje específico. Conjunto de bronces y placas de opus signinum procedentes del sector residencial.

- Origen situado en torno al cambio de Era aunque las primeras estructuras remarcables se fechan entre la segunda mitad del s. I y el s. II cuando se construye el sector residencial. Hacia el s. III se inutiliza el sector residencial y en el s. IV se construyen nuevas habitaciones dedicadas a actividades de tipo productivo que se abandonan en el s. V. Una vez abandonadas, las estructuras se reaprovechan como espacio funerario.

- J. Massó y E. Ramón, 1993: "La vil·la romana de ‘la Llosa”', Revista Cambrils, I50, pp. 357-373; M. García, J. M. Macías e I. Teixell, 1999: "Món funerari del territori de Tarraco", Del romà al romànic, p. 277. 


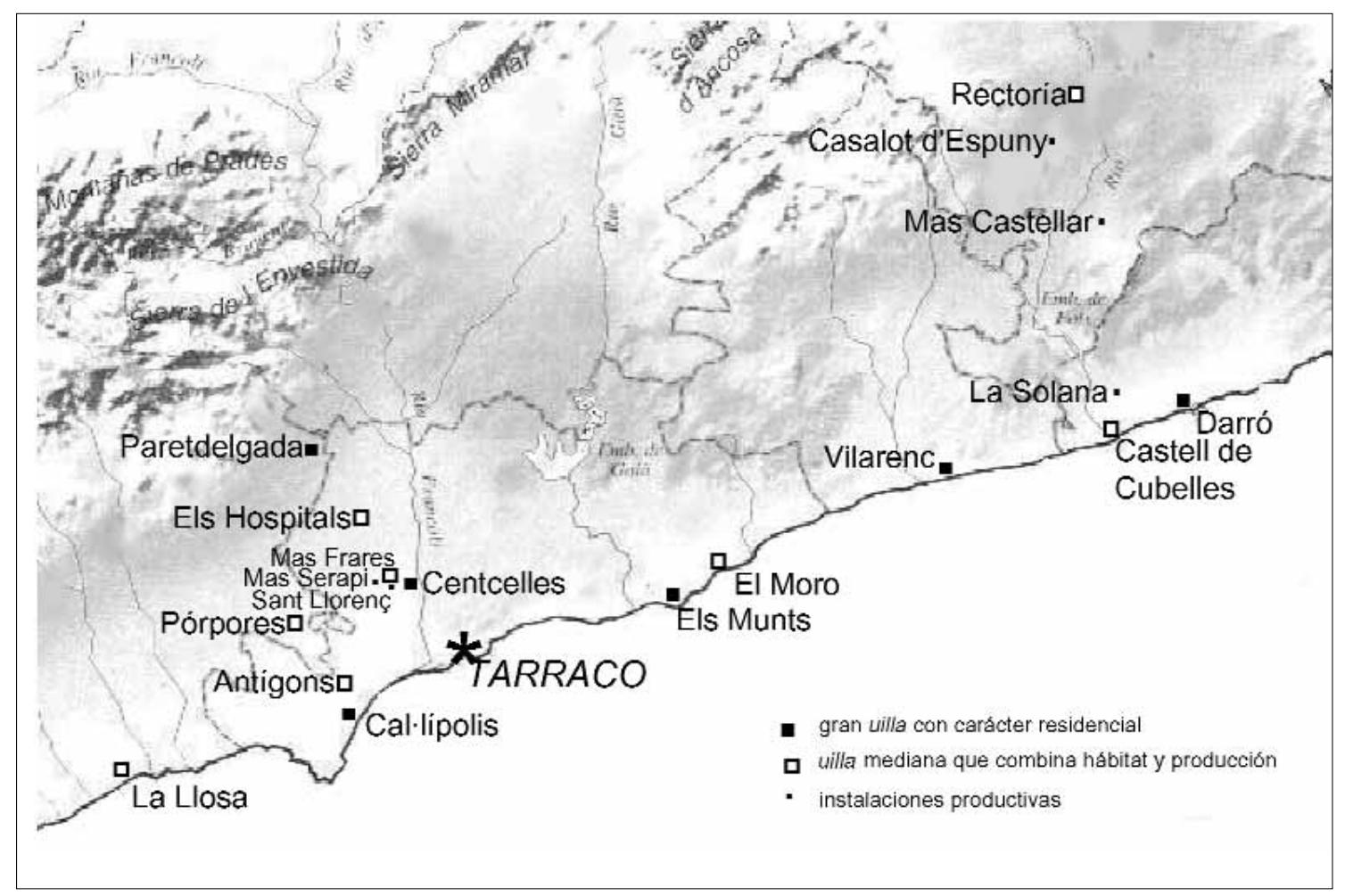

Fig I. El territorium de Tarraco con los establecimientos rurales mencionados en el texto

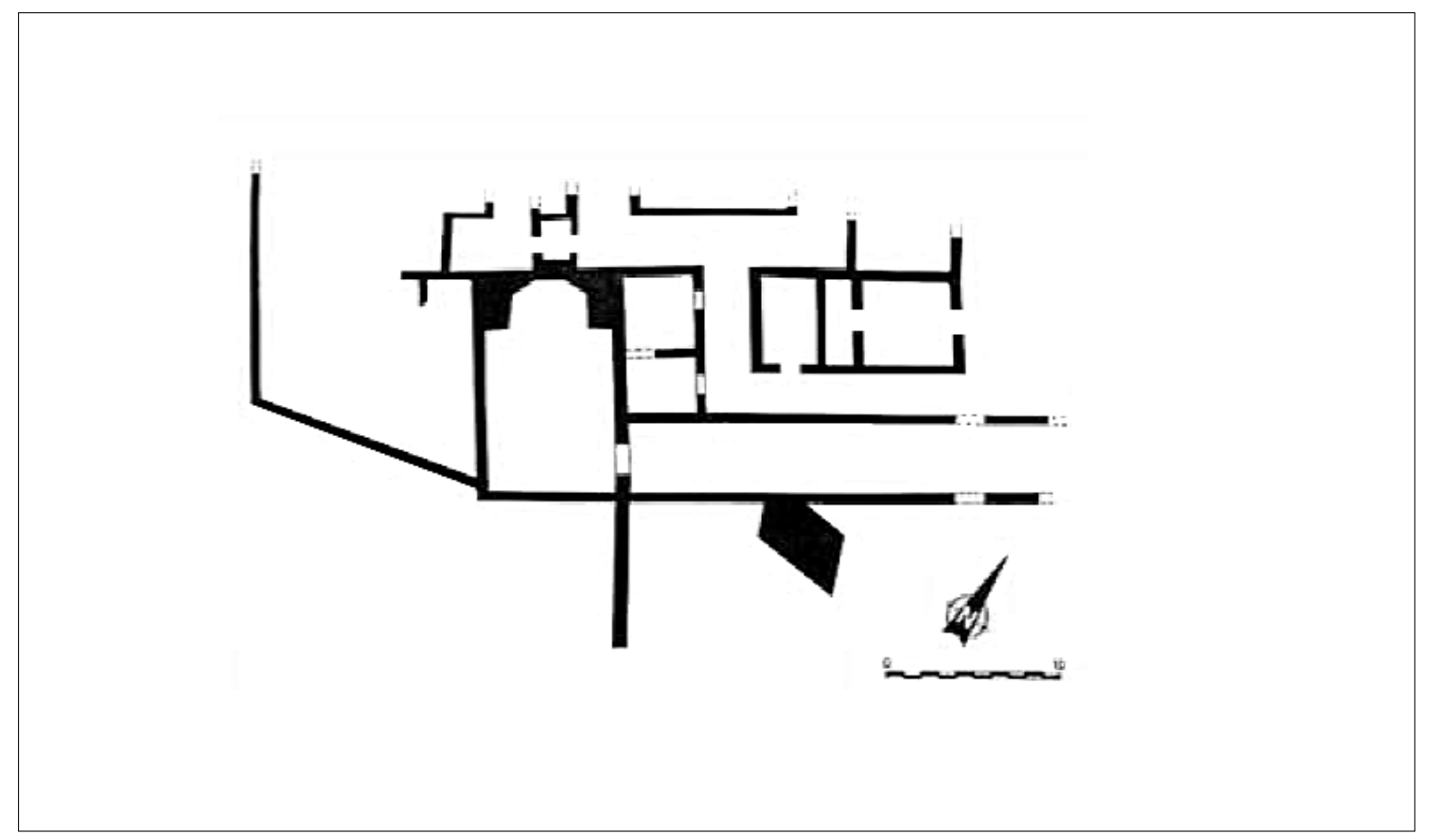

Fig 2. Darró (Vilanova i la Geltrú) durante la antigüedad tardía (según López y Fierro, 1990 con modificaciones de Chavarría) 


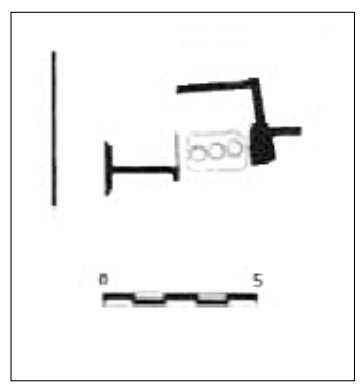

Fig. 3. La Rectoria (Pacs del Penedès)

(según Balil, 1987 con modificaciones

de Chavarría)

Fig. 4. El Moro (Torredembarra) (según Terré, 1987, con modificaciones de Chavarría)
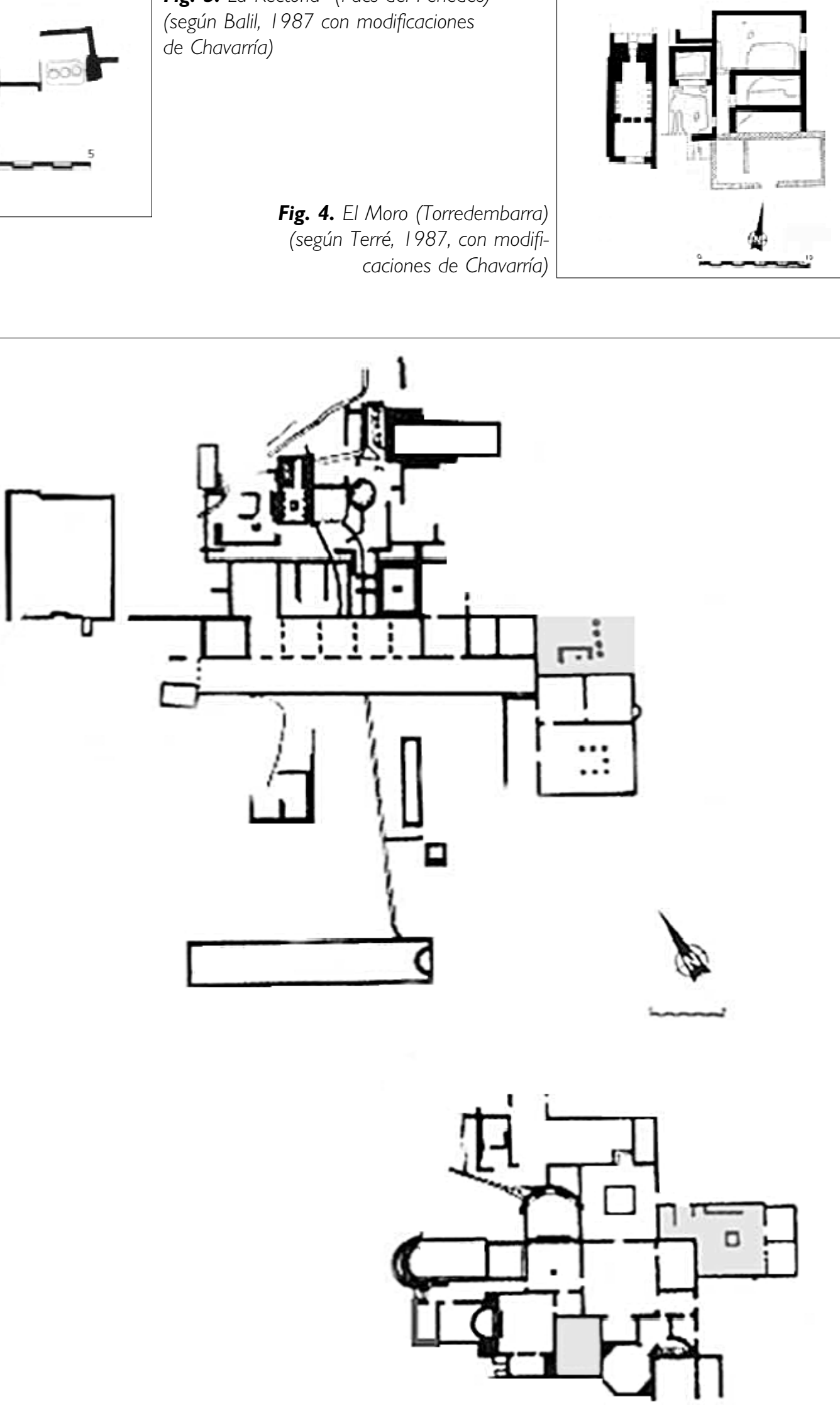

Fig. 5. Els Munts (Altafulla) (según Berges, 1969-70 con modificaciones de Chavarría) 


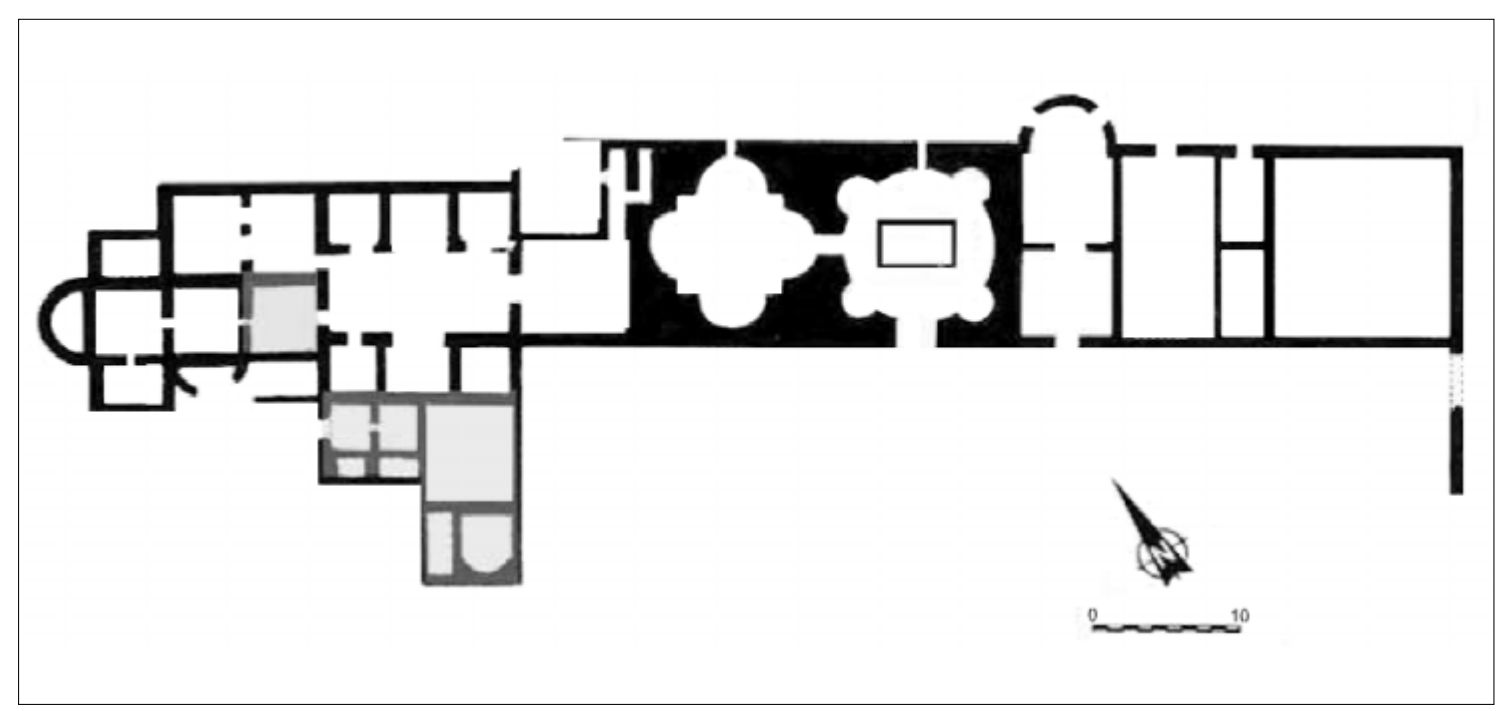

Fig 6. Centcelles (Constanti) (según Schlunk, 1988 con modificaciones de Chavarría).

El punteado gris indica las zonas donde se han documentado transformaciones.

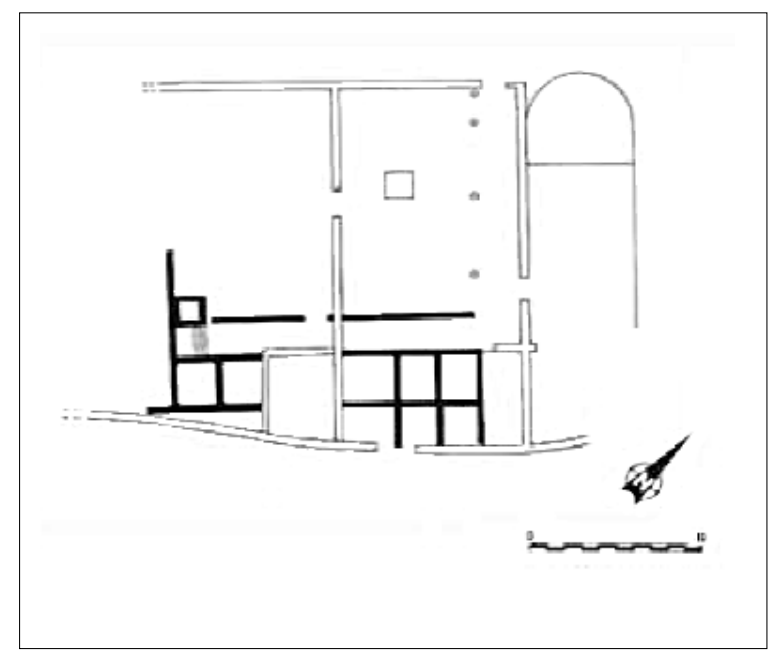

Fig 7. Paretdelgada (La Selva del Camp) (según Guitert, 1936 con modificaciones de Chavarría)

Fig. 8. La Llosa (Cambrils)

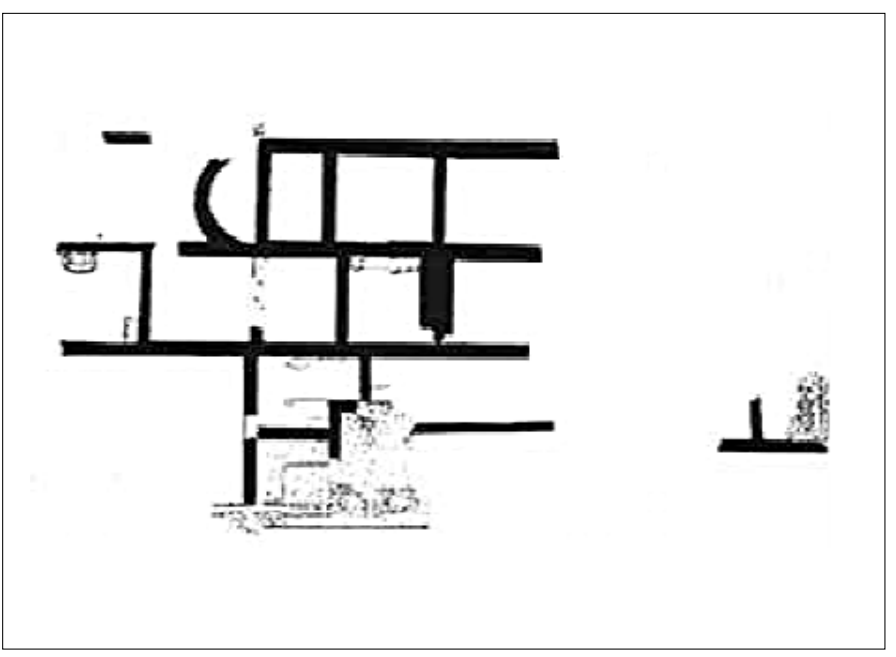

(según Massó y Ramón. con modificaciones de Chavarría) 


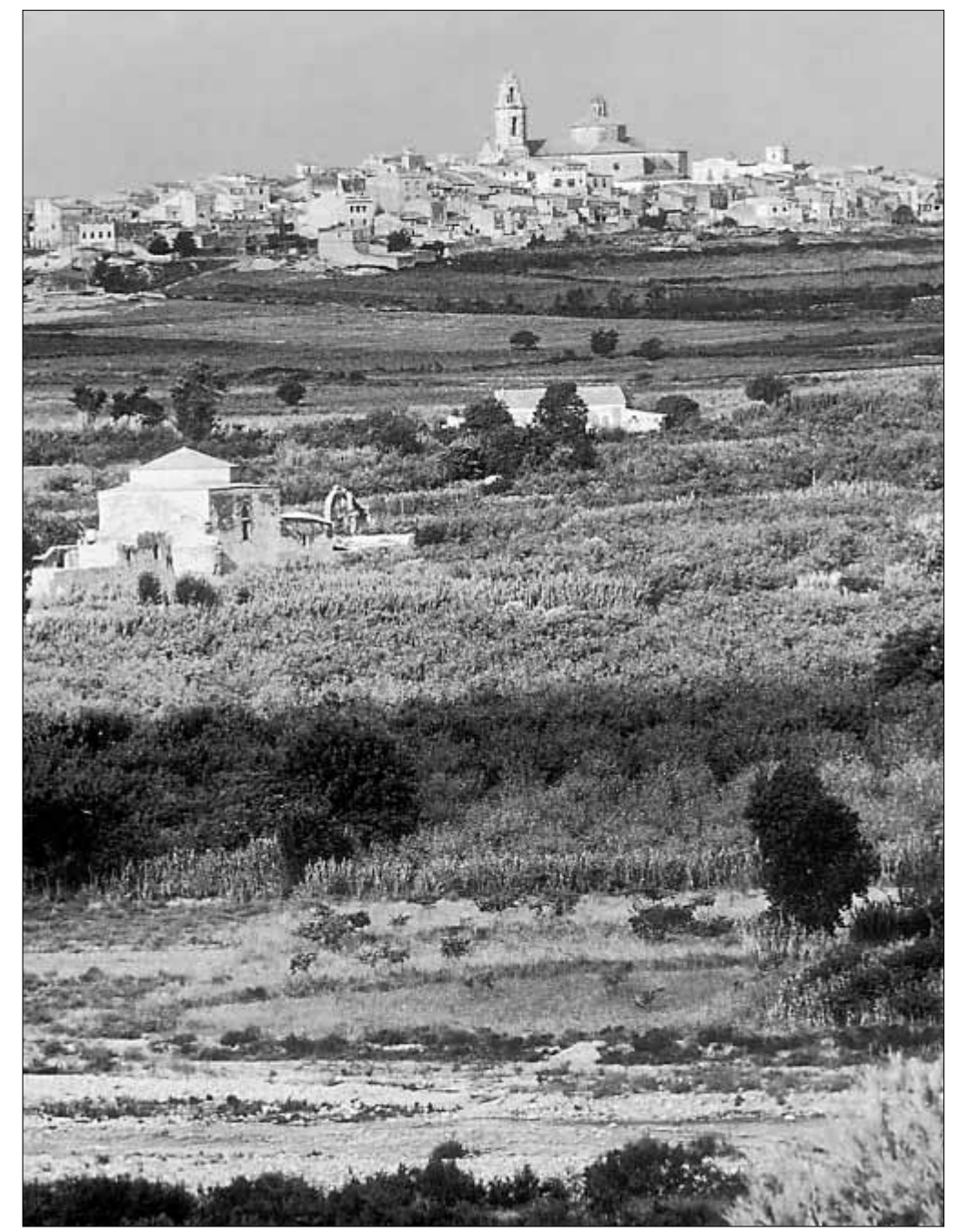

Lámina I. Centcelles y Constantí, donde se han documentado numerosos yacimientos de tipo rural (fotografia de Schlunk, 1988).

Lámina 2.

Necrópolis de Els Munts (Del romà al romànic, 1999, p. 278)

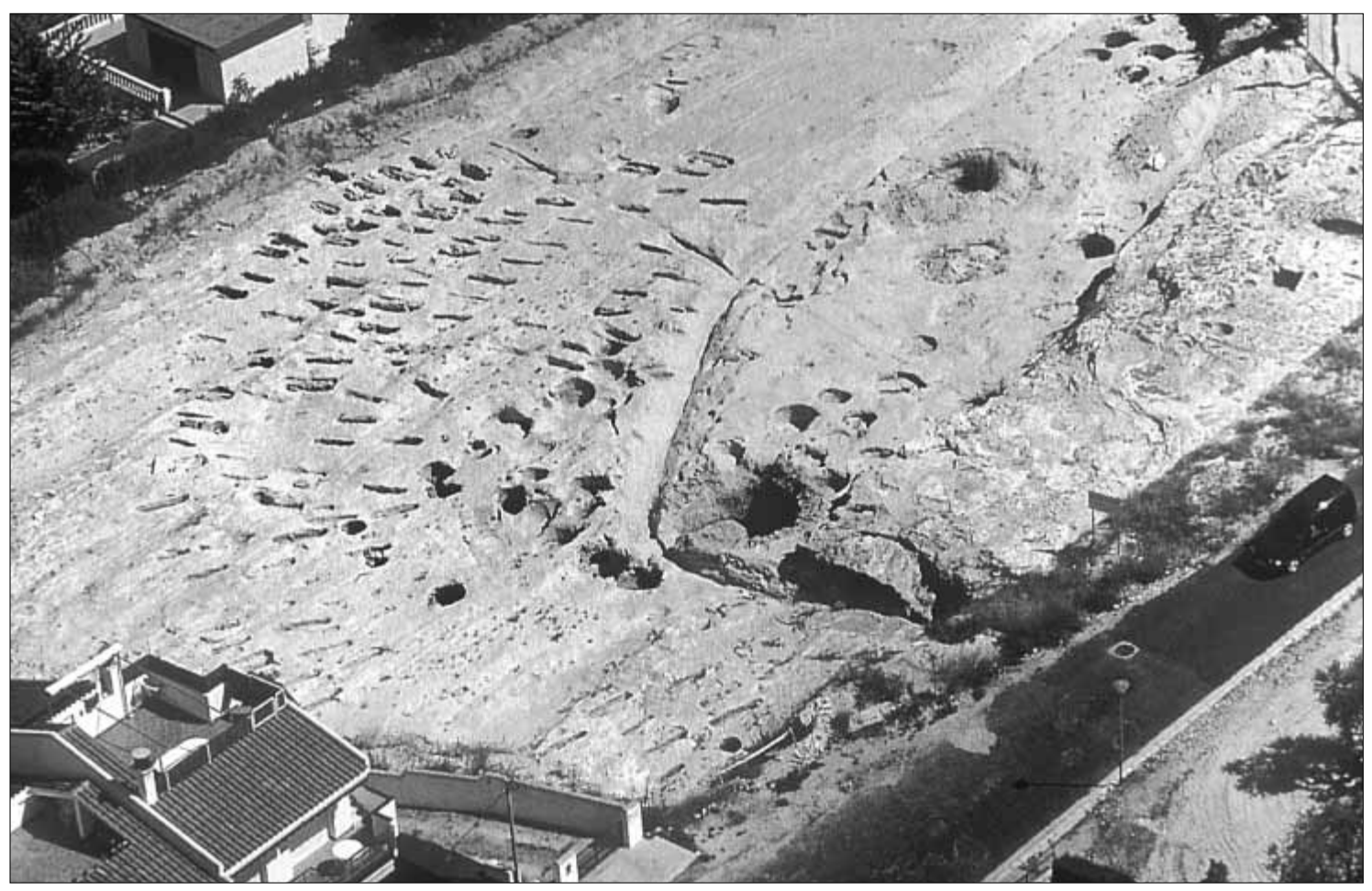




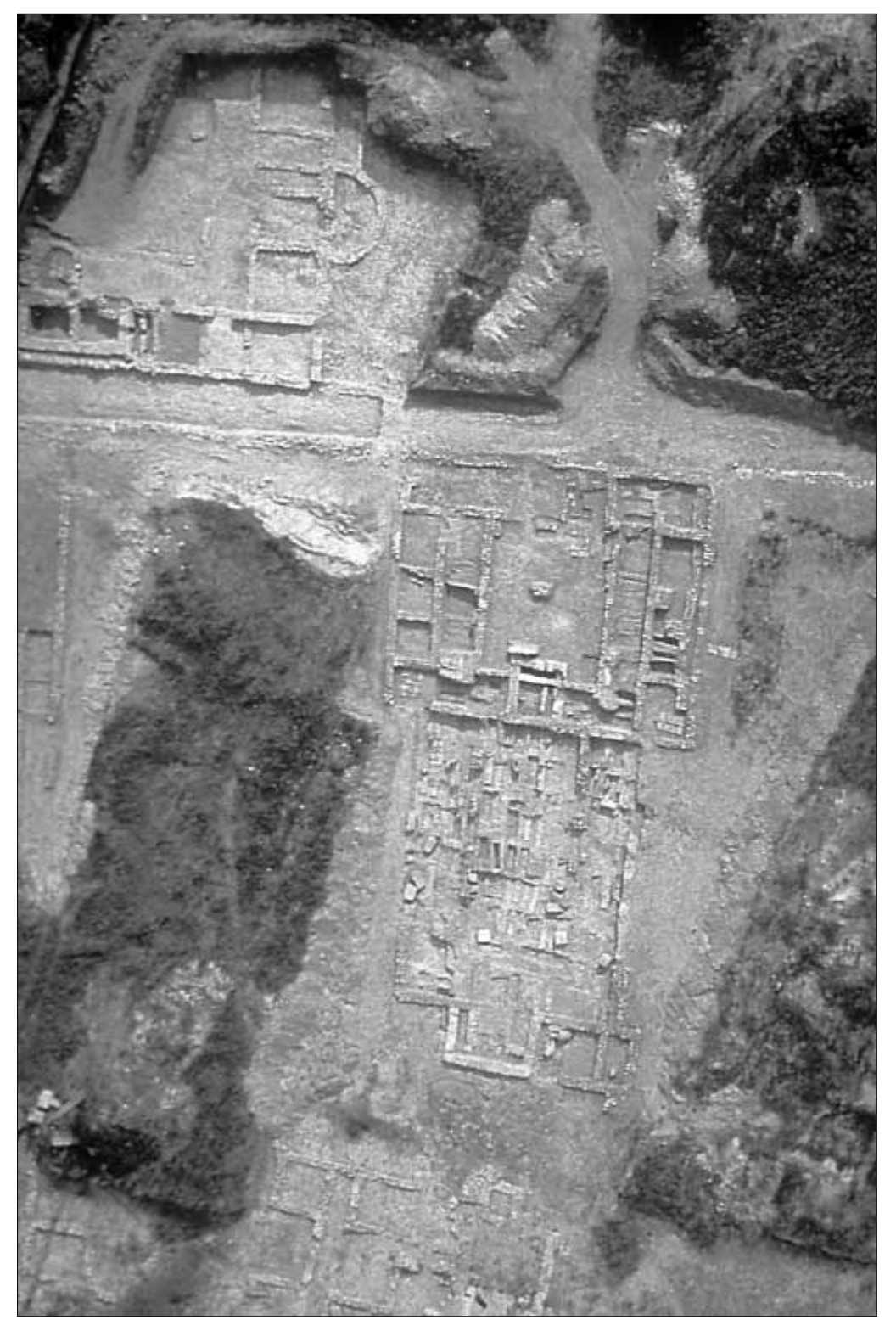

Lámina 3. Yacimiento del Parc Central. (Del romà al romànic, 1999, p. 175)

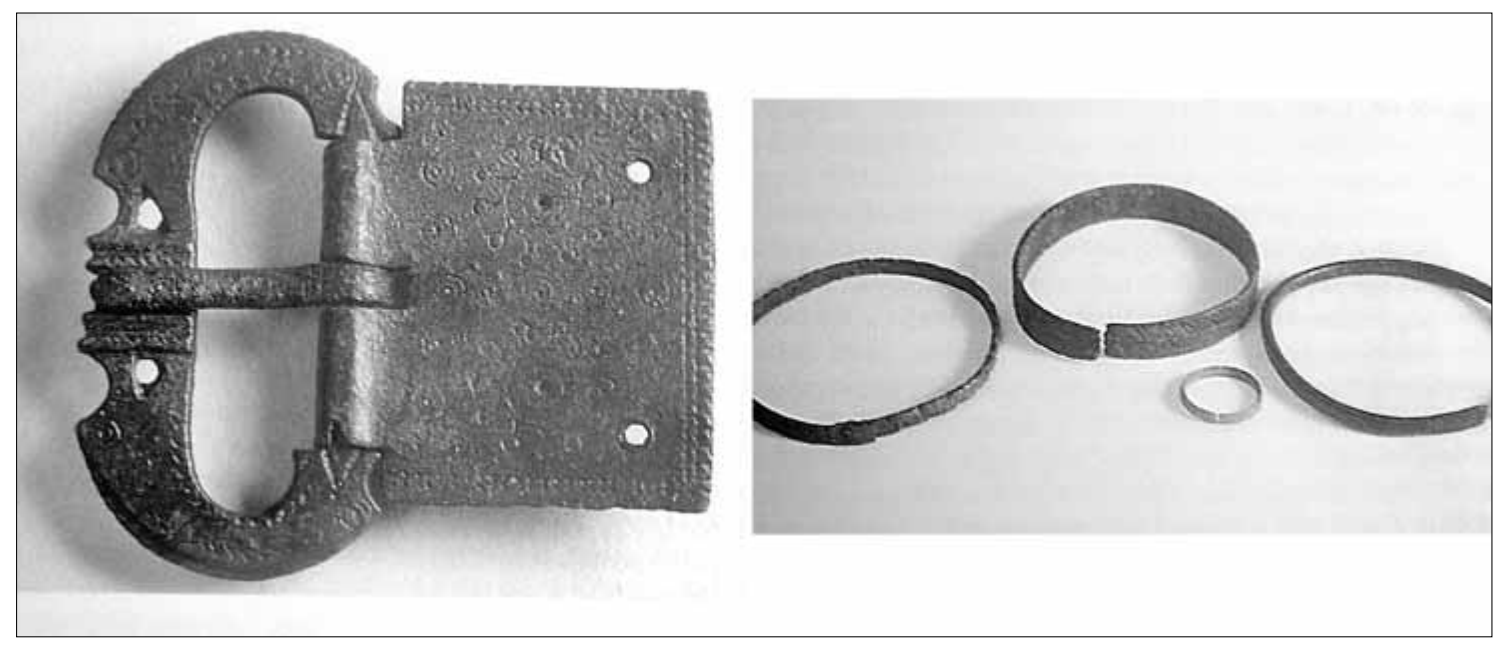

Lámina 4. Algunos materiales documentados en una de las tumbas de la villa de La Llosa. (Del romà al romànic, 1999, p. 315) 